(Aus der ernährungs-physiologischen Abteilung des Instituts für Gärungsgewerbe der Kgl. Iandwirtsch. Hochschule zu Berlin.)

\title{
Über die vom tierischen Organismus unter verschiedenen Bedingungen ausgeschiedenen Alkoholmengen.
}

\author{
Von \\ Wilhelm Völty und August Baudrexel.
}

(Mit 3 Textfiguren.)

Vor kurzem haben wir an dieser Stelle ${ }^{1}$ ) über Versuche an Hunden berichtet, welche angestellt wurden, um die in Harn und Atmung zur Ausscheidung gelangten Alkoholmengen quantitativ zu bestimmen. Bezüglich der Apparatur und der Methodik haben wir bereits ausführliche Angaben gemacht und auch einige Versuchsresultate mitgeteilt. Hier sei nur kurz rekapituliert, dass wir einen grossen Vakuumtrockenapparat nach entsprechenden Abänderungen als Respirationsapparat benutzten, um den ausgeatmeten Alkohol zu bestimmen. Das Wesentliche ist aus der Fig. 1 auf S. 86 und der Beschreibung der einzelnen Teile ersichtlich.

Für die Bestimmung des Alkohols im Harn benutzten wir die Nicloux'sche ${ }^{2}$ ) Methode; ebenso kam diese Methode entsprechend modifiziert bei der Analyse des durch die Atmung ausgeschiedenen Alkohols zur Anwendung. $\mathrm{Zu}$ dem Zweck wird in die Vorlage, welche die durch den Respirationsapparat gesaugte Luft passiert, eine Lösung von Kaliumbichromat und Schwefelsäure von bekanntem Alkoholoxydationsvermögen gebracht. Nach Beendigung des Ver-

1) W. Völtz (Referent), R. Förster und A. Baudrexel, Über die Verwertung des Bierextraktes und des Bieres im menschlichen und tierischen Organismus. Pflüger's Arch. Bd. 134 S. 138. 1910.

2) M. Nicloux, Dosage de l'alcool dans le chloroform. Bull. de la Soc. Chimique de Paris (3e sér.) T. 35 p. 330. 1906. 
suches wird durch Titration eines aliquoten Teiles der vorgelegten Lösung gegen eine wässerige $0,1 \%$ ige alkoholische Lösung bestimmt, wieviel Alkohol die gesamte vorgelegte Bichromat-Schwefelsäurelösung noch zu oxydieren vermag. Aus der Differenz des so gefundenen Wertes und des Wertes für das ursprüngliche Alkoholoxydationsvermögen der vorgelegten Lösung ergibt sich die Zahl für den in

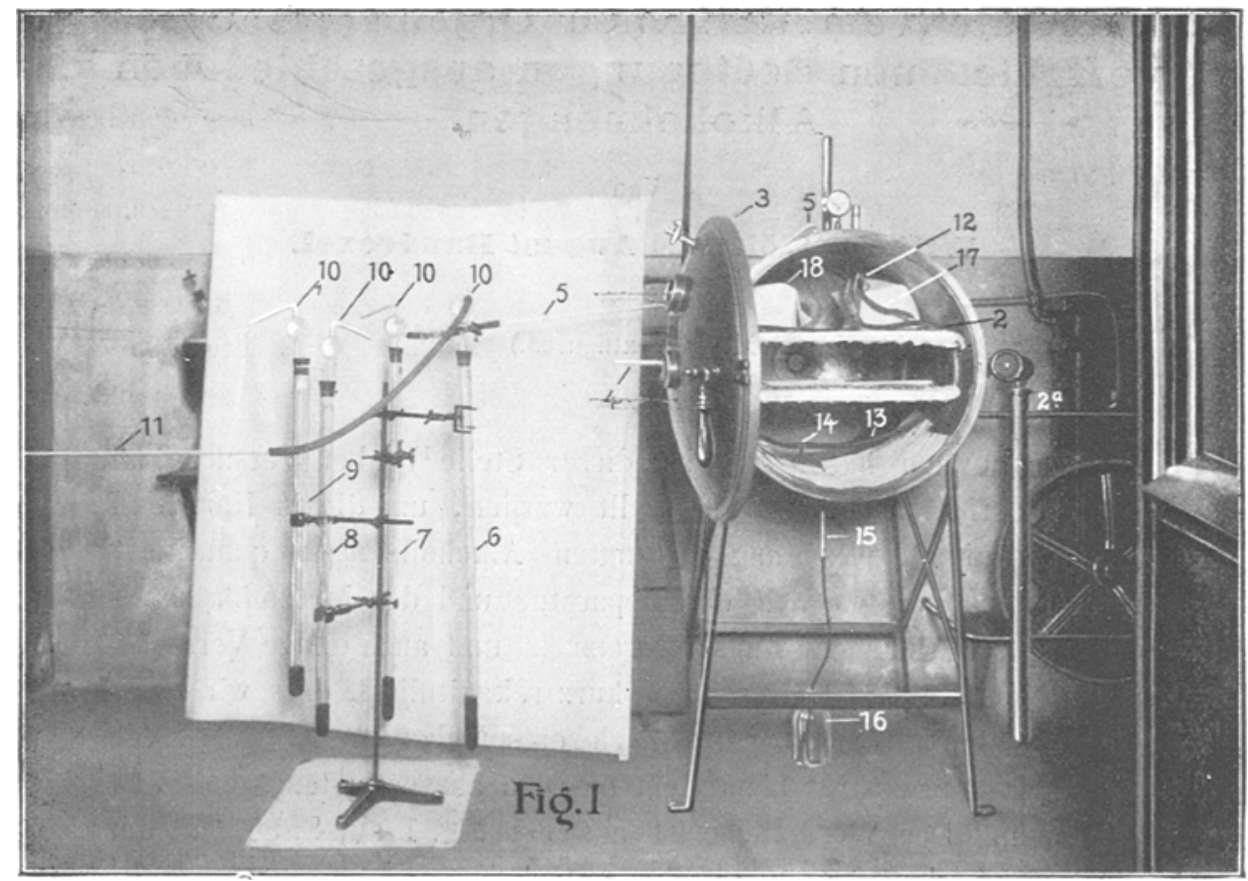

Fig. 1. Modifizierter Vakuurntrockenapparat für Respirationsversuche. 2 und 2 a Heizplatten. 3 Türe. 4 Glasrohr, durch das die atmosphärische Luft in den Apparat gelangt. 5 Glasrohr, durch das die Luft aus dem Apparat durch die Vorlagen 6 bzw. 7,8 oder 9 gesangt wird. 10 Aufsätze, die ein Mitreissen von Tropfen der Lösung mit der abströmenden Luft verhindern. 11 Verbindungsrohr zwischen Vorlage und Pumpe. 12 Harntrichter für männliche Hunde. 13 Gummischläuche, die durch das $T$-Rohr 14 zum Abflussrohr 15 für den Harn führen. 16 mit angesäuertem Wasser beschickte Flasche zur Aufnahme des Harnes. 17 und 18 seitliche Einsätze, die die Bewegungen des Hundes beschränken. Die Befestigung des Tieres, die aus der Abbildung nicht zu ersehen ist, erfolgt mittelst Halsbandes und zwei seitlicher Ketten an entsprechenden Ansätzen vorn an der oberen Heizplatte 2 .

der Atmung abgegebenen Alkohol (Genaueres siehe in der unter 1 zitierten Arbeit S. 181-184).

In drei Fallen bestimmten wir die in den Harn übergehenden Alkoholmengen an Menschen. Die Herren Dr. med. H. Gerhartz, Dr. med. R. Förster und der eine von uns (Ba udrexel) stellten 
sich für diese Versuche, auf die später eingegangen werden wird, zur Verfügung.

Die gesamte vom Organismus ausgeschiedene Alkoholmenge (also in Harn und Atmung) wurde nur an Hunden festgestellt. Die Tiere erhielten den Alkohol zumeist nach der Fütterung, die morgens erfolgte, mittels Schlundsonde. Bei einer Versuchsreihe, bei der der Alkohol in konzentrierterer Form (ca. $50 \% \mathrm{ig}$ ) zur Verwendung gelangte, wurde derselbe der ersten Futterportion zugemischt und von dem Tier stets sofort mit dem Futter aufgenommen; unmittelbar darauf erhielt der Hund den Rest des Futters in einer zweiten Portion vorgesetzt und wurde gleich nach dem Verzehr (nach längstens fünf Minuten) in den Respirationsapparat gebracht. Das Futter bestand aus gemischter Kost (Fleisch, Kartoffeln, Brot resp. Reiss und aus Fett). Die einzelnen Versuche dauerten 18-24 Stunden, da wir uns davon überzeugt hatten, dass nach dieser Zeit kein Alkohol mehr vom Organismus ausgeschieden wird. Die Tiere waren stets in dem Respirationsapparat so fixiert, dass ihre Bewegungsfähigkeit sehr beschränkt war, und dass wir somit diese Versuche als Ruheversuche zu betrachten haben. Allenfalls war es den Tieren möglich aufzustehen, jedoch kam das sehr selten oder nie vor. Wir haben die Hunde häufig durch ein Fenster des Apparates beobachtet und dieselben jedenfalls nur liegend gesehen. Nach der Beendigung der Versuche wurde der in der Blase noch vorhandene Harn zur Alkoholbestimmung gewonnen, und zwar bei einem grossen älteren Hunde durch Katheterisieren, bei den jungen Hunden durch Anwendung der 'Z u n t z' schen Methode ${ }^{1}$ ) der Harnabgrenzung. Das erste Harndestillat wurde stets neutralisiert; hierauf erfolgte die zweite Destillation und die Alkoholbestimmung.

Wir studierten den Einfluss folgender drei Faktoren auf die Ausscheidung des Alkohols durch den tierischen Organismus: A der Quantität, B der Gewöhnung und C des Flüssigkeitsvolums.

A. Einfluss der aufgenommenen Alkoholmengen auf die Ausscheidung des Alkohols in Harn und Atmung.

Wir wählten vier männliche Hunde für unsere Versuche, und zwar erstens ein älteres Tier (Kreuzung von Teckel mit einer

1) Pollitzer, Über den Nährwert einigerVerdauungsprodukte des Eiweisses. Pflüger's Arch. Bd. 37 S. 30 . 
anderen Hunderasse) und zweitens drei junge Hunde desselben Wurfes (Kreuzungsprodukte von männlichem Teckel und Terrierhündin), die hier geboren und bei Beginn der Versuche 6-7 Monate alt waren.

\section{Versuche an dem älteren Tier.}

Der ältere, ca. $8 \mathrm{~kg}$ schwere Hund erhielt etwa 3 cem Alkohol pro Körperkilogramm pro die, und zwar zunächst nicht täglich, sondern nur an bestimmten Versuchstagen, die je durch 1-4 Tage voneinander getrennt waren, an denen das Tier alkoholfreie Kost erhielt. Nach einiger Zeit, als wir den Einfluss der Gewöhnung auf die Alkoholausscheidung an demselben Hund studierten, erhielt er regelmässig täglich, also wenn er sich auch nicht im Versuch befand, $2 / 3$ der an den Versuchstagen verabreichten Alkoholmenge.

Bei den ersten vier Versuchen an diesem Tier gelang es nicht, den Harn quantitativ nach aussen abzuleiten, weil der Trichter zunächst nicht gut passte. Es sammelten sich nicht unerhebliche Mengen Harn in dem Apparat an, die natürlich ihren Alkohol, teils während der Luftdurchströmung durch den Apparat, teils nach der Erwärmung und der Evakuierung desselben nach Abschluss jedes Versuches an die Bichromatschwefelsäurevorlage abgaben. Es sind infolgedessen die Zahlen für die in Harn und Atmung zusammen ausgeschiedenen Alkoholmengen einwandfrei. Um aber auch für diese vier Versuche annähernd zu erfahren, wieviel Alkohol im Harn, wieviel durch die Atmung ausgeschieden wurde, haben wir das Tier in drei besonderen Versuchen ausserhalb des Respirationsapparates mit Harntrichter ausgerüstet und fixiert, hierauf die gleiche Alkoholmenge mittels Schlundsonde in den Magen gebracht und den während 24 Stunden gelassenen Urin quantitativ gesammelt und auf Alkohol untersucht. Bei den späteren Versuchen gelang die Abführung des Harns aus dem Apparat leicht vollständig durch die Benutzung eines besser passenden Harntrichters. Bevor die Tierversuche angestellt wurden, batten wir uns durch besondere Versuche ${ }^{1}$ ) davon überzeugt, dass es gelingt, in den Apparat gegossene, bekannte Alkoholmengen in den Vorlagen quantitativ zu bestimmen. Ferner stellten wir fest,

1) Eine Anzahl der gefundenen Werte sind in der früheren Publikation, l. c., mitgeteilt. Wir bemerken, dass die Abweichungen von den theoretischen Werten bei den ersten diesbezüglichen Versuchen gefunden wurden; bei den späteren war die Übereinstimmung eine nahezu vollständige. 
dass der Titer der Bichromat-Schwefelsäurevorlage unverändert blieb, wenn wir 24 Stunden Luft durch den leeren Apparat saugten; die Zimmerluft enthielt also keine reduzierenden Stoffe. Hierauf war die Frage zu entscheiden, wieviel reduzierende Substanzen von Hunden bei alkoholfreiem Regime durch die Atmung abgegeben werden. (Harndestillate enthalten bei alkoholfreier Nahrung, wie wir uns überzeugten, keine solchen Substanzen.)

Bei Menschen hatten Atwater und Benedict ${ }^{1}$ ) bekanntlich bei alkoholfreiem Regime im Mittel eine 0,3 g Alkohol entsprechende Menge dieser Stoffe innerhalb 24 Stunden nachgewiesen.

Wir hatten an vier Hunden, und zwar:

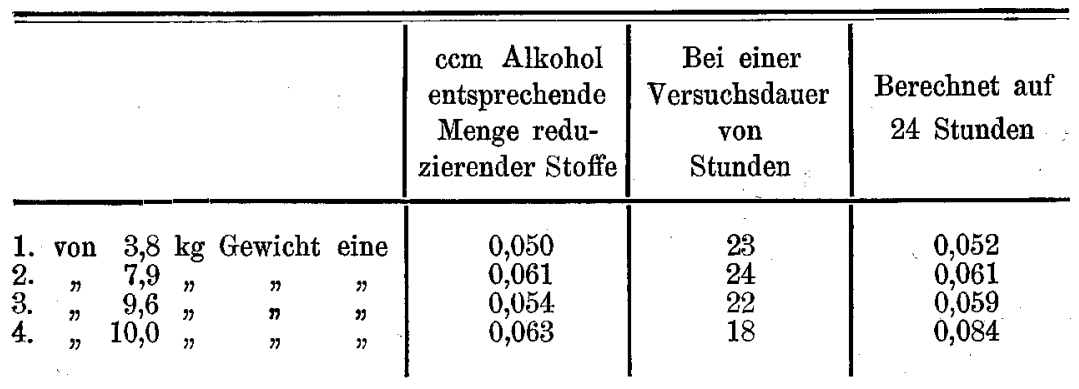

also im Mittel von $21^{3 / 4}$ Stunden $0,057 \mathrm{ccm}$, bzw. auf 24 Stunden berechnet im Mittel $0,064 \mathrm{ccm}$ gefunden, also annähernd übereinstimmende Werte für die Gewichtsdifferenzen von $3,8-10,0 \mathrm{~kg}$.

Den Wert $0,064 \mathrm{ccm}$ für 24 Stunden bringen wir bei sämtlichen Alkoholversuchen für die entsprechende Anzahl Stunden umgerechnet in Abzug. Bei einem Gespräch, welches der eine von uns (Völ tz) gelegentlich mit Geheimrat N. Zuntz über die Resultate der vorliegenden Untersuchung hatte, regte derselbe an, doch auch beim hungernden Tier die reduzierenden Stoffe zu bestimmen. Wir haben an zwei Hunden von 9,3 und $7,4 \mathrm{~kg}$ Gewicht bei dem grösseren nach 9 tägigem, bei dem kleineren nach 6 tägigem Hunger diese Bestimmungen ausgeführt. Es ergaben sich folgende Resultate für die beiden Versuche von je 22 stündiger Dauer. Von dem grösseren Hunde wurden an reduzierenden Stoffen abgegeben:

1) W. 0. Atwater and F. G. Benedict, An exp. inquiry regarding the nutritive value of Alcohol. Mem. of the nat. acad. of sciences vol. 8 p. 6 memoir. Washington 1902. 
von dem kleineren Hunde eine 0,019 ,

$\begin{array}{cc}\text { durch die Atmung } & \text { durch den Harn } \\ \text { eine } 0,017 \mathrm{cem} & 0 \\ \text { eine } 0,019 & 0\end{array}$

Alkohol entsprechende Menge, also im Mittel 0,018 ccm, das sind nur rund $32 \%$ des bei normal ernährten Tieren gefundenen Mittelwertes.

In einer Anzahl Versuche haben wir den in Harn und Atmung nach bestimmten Zeitabschnitten je eines Versuchstages ausgeschiedenen Alkohol gesondert bestimmt, um den Verlauf der Alkoholausscheidung festzustelIen. Die Details sollen bei der nun folgenden Besprechung der einzelnen Versuche mitgeteilt werden.

Zur Erleichterung der Übersicht über die erste Versuchsreihe lassen wir zunächst die Tabelle I folgen.

Tabelle 1 .

Übersicht über die Versuchsreihe an dem älteren Tier.

\begin{tabular}{|c|c|c|c|c|}
\hline $\begin{array}{c}\text { Datum } \\
1910\end{array}$ & $\begin{array}{l}\text { Ver- } \\
\text { such } \\
\text { Nr. }\end{array}$ & $\begin{array}{c}\text { Zufuhr } \\
\text { von Alkohol } \\
\text { in } 9,84 \% \text { iger } \\
\text { Lösung } \\
\text { ccm }\end{array}$ & $\begin{array}{c}\text { Alkohol- } \\
\text { bestimmungen }\end{array}$ & $\begin{array}{c}\text { Ver- } \\
\text { suchs- } \\
\text { dauer } \\
\text { Stunden }\end{array}$ \\
\hline 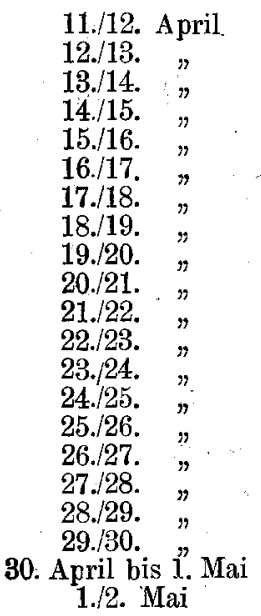 & $\begin{array}{l}\overline{2} \\
3 \\
\overline{-} \\
\overline{4} \\
\frac{4}{5} \\
\frac{6}{7} \\
\frac{7}{8} \\
\frac{8}{5} \\
- \\
-\end{array}$ & $\begin{array}{l}29,49 \\
29 ; 25 \\
- \\
\bar{Z} \\
29,49 \\
29,29 \\
\overline{29,49} \\
20 \\
29,49 \\
20 \\
29,49 \\
20 \\
20 \\
29,49 \\
20 \\
20 \\
20\end{array}$ & $\begin{array}{l}\text { im Harn und in der Atmung } \\
\text { in der Atmung } \\
\text { im Harn und in der Atmung } \\
\text { im Harn } \\
\text { im Harn und in der Atmung } \\
\text { im Harn und in der Atmung } \\
\text { im Harn und in der Atmung } \\
\qquad \text { im } \overline{-} \\
\text { - }\end{array}$ & $\begin{array}{l}\frac{23}{23} \\
24 \\
\frac{-}{2} \\
\overline{21} \\
\frac{22}{21} \\
\overline{22} \\
\frac{21}{2} \\
\frac{2}{2} \\
=\end{array}$ \\
\hline
\end{tabular}

Vom 2./3. Mai bis 26./27. Mai erhielt das Tier an sieben Versuchtagen, auf die später eingegangen werden wird, (siehe S. 102 und Tab. 5 S. 104) je $29,74 \mathrm{ccm}$ Alkohol täglich in konzentrierterer Form (50\% ig) und an den Zwischentagen je $20 \mathrm{ccm}$. Nach Absehluss dieser Versuche wurden am 27./28. Mai in einem letzten Versuch (Nr. 10) wieder 29,49 cem Alkohol in 9,84\% \% iger Lösung 
gegeben und der in Harn und Atmung ausgeschiedene Alkohol bestimmt $\left(21^{1 / 2}\right.$ Stunden Versuchsdauer).

Nunmehr gehen wir auf die Beschreibung der einzelnen Versuche ein.

\section{1., 2. und 3. Versuch.}

Der $8,2 \mathrm{~kg}$ schwere ältere Hund erhält am 11. April 1910 nach der Fütterung um 10 Uhr morgens 29,49 cem Alkohol in 9,84 volumprozentiger Lösung, entsprechend pro Körperkilogramm $3,60 \mathrm{ccm}$, und wird hierauf mit Harntrichter armiert in den Apparat gebracht. Nach ea. 11/2 Stunden bellte und heulte der infolge der sebr grossen Alkoholgabe stark bezechte Hund ca. 3 Stunden lang mit nur kurzen Unterbrechungen. Das Tier zeigte forciertë Atmung. Nach der angegebenen Zeit verhielt es sich ruhig bis zum Abschluss des Versuches, der nach insgesamt 23 stündiger Dauer erfolgte. Es waren, wie bereits einleitend erwähnt, nicht unbeträchtliche Mengen Harn in dem Apparat verblieben, die nach Entfernung des Hundes durch Schliessen des Apparates, Erwärmung der Heizplatten und Evakuierung des Apparates vom Alkohol befreit wurden, welcher in die Bichromatvorlage überdestilliert und oxydiert wurde. Das Tier wurde sofort nach Beendigung des Versuches katheterisiert und der so gewonnene Harn mit dem im Harngefäss während des Versuches gesammelten vereinigt und nach der Nicloux'schen Methode auf Alkobol untersucht. Die Alkoholbestimmung des gasförming aus dem Apparat in die Vorlagen gelangten Alkohols erfolgte in der in der früheren Publikation (l. c.) genau beschriebenen Weise. Es wurden im Harn ermittelt $0,494 \mathrm{ccm}$. Alkohol $=1,67 \%$ der Zufuhr, im Destillat 2,988 ccm Alkohol; hiervon sind zu subtrahieren $=0,061 \mathrm{ccm}$ für die reduzierenden Substanzen (berechnet für 23 Stunden), so dass also 2,927 cem Alkohol in das Destillat übergegangen waren, entsprechend $9,9 \%$ der Zufuhr. Bei diesem Wert ist $\mathrm{zu}$ berücksichtigen, dass ein Teil dieses Alkohols dem Harn entstammt. Insgesamt wurden in Harn und Atmung $3,421 \mathrm{ccm}$ Alkohol, entsprechend $11,6 \%$ der Zufuhr, gefunden. Dieser Wert für die Gesamtausscheidung ist natürlich einwandfrei.

Um nun die im Harn allein ausgeschiedene Alkoholmenge annähernd genau zu erfahren, wurde am übernächsten Tage, also am 13. April, in einem $\mathrm{z}$ weiten Versuch dieselbe Menge Alkohol unter gleichen Bedingungen verabreicht, nur wurde der Hund nicht in den Apparat gebracht, weil wir den Harn allein zur Alkohol- 
bestimmung quantitativ gewinnen wollten. Zu dem Zweck wird der mit Harntrichter armierte Hund in einer zweckentsprechend konstruierten Kiste befestigt. Der Kopf wird durch eine Öffnung herausgesteckt. Der Boden wurde durchbohrt, um den Trichteransatz hindurchzuführen, von dem ein Schlauch den Harn in ein entsprechendes Glasgefäss leitete. Der $8,1 \mathrm{~kg}$ schwere Hund erhielt $29,25 \mathrm{ccm}$ Alkohol, also pro Körperkilogramm $3,62 \mathrm{ccm}$, und schied innerhalb 23 Stunden 1,650 cem Alkohol $=5,64 \%$ im Harn aus. Der Hund war ebenso stark berauscht und heulte in gleicher Weise wie beim ersten Versuch. Bei den späteren Versuchen war der Rausch infolge der Gewöhnung weniger stark, das Tier heulte jedoch noch immer einige Zeit.

Vier weitere Versuche, in denen bei stets gleicher Alkoholzufuhr (ca. 3,3 cem pro Körperkilogramm) die durch die Nieren sezernierte Alkoholmenge quantitativ bestimmt wurde, ergaben folgende Werte:

\begin{tabular}{c|c|c|c|c|c|c|c}
\hline \hline Datum & $\begin{array}{c}\text { Ver- } \\
\text { such 5 }\end{array}$ & Datum & $\begin{array}{c}\text { Ver- } \\
\text { such 8 }\end{array}$ & Datum & $\begin{array}{c}\text { Ver- } \\
\text { such 9 }\end{array}$ & Datum & $\begin{array}{c}\text { Ver- } \\
\text { such 10 }\end{array}$ \\
\hline 19./20. April & $4,06 \%$ & 25./26. April & $5,83 \%$ & $28 . / 29$. April & $5,33 \%$ & 27./28. Mai & $5,86 \%$
\end{tabular}

Im Mittel dieser Zahlen und der eben mitgeteilten für den zweiten Versuch $(5,64 \%)$ berechnet sich als Durchschnittswert die Zahl $5,43 \%$. Die Versuche wurden innerhalb eines Zeitraumes von $6^{1 / 2}$ Wochen ausgefuhrt. Für die ersten vier Versuche an diesem Hund, in denen die quantitative Trennung das Harnalkohols von dem Alkohol der Atmung nicht gelang, haben wir den Mittelwert 5,34 für den Alkohol des Harnes eingesetzt und durch Subtraktion von dem gefundenen Gesamtwert die in der Atmung ausgeschiedene Alkoholmenge bestimmt.

Aus den eben mitgeteilten Zahlen für den Alkohol des Harnes geht hervor, dass die gefundenen und mit (iner Ausnahme (5. Versuch) geringen Abweichungen unabhängig von der Gewöhnung an Alkohol sind, während im Gegensatz hierzu, wie wir noch sehen werden, die durch die Atmung abgegebenen Alkoholmengen allmählich geringer werden. Bei dem vorliegenden ersten Versuch wurden, wie bereits erwähnt, insgesamt $3,421 \mathrm{ccm}=11,6 \%$ des aufgenommenen Alkohols in Harn und Atmung ausgeschieden, und zwar 1,574 $\mathrm{ccm}=5,3 \%$ $\mathrm{i}_{\mathrm{m}}$ Harn und $1,847 \mathrm{ccm}=6,3 \%$ in der Atmung; resp. in Prozenten der Gesamtausscheidung im Harn $46 \%$, in der Atmung $54 \%$. 
Un uns davon zu überzeugen, ob noch 24 Stunden nach einer Alkoholzufuhr, wie wir sie gewählt hatten, nämlich $3,6 \mathrm{ccm}$ pro Körperkilogramm, Alkohol unverbrannt zur Ausscheidung gelangt, erhielt der Hund am 13./14. die angegebene Menge Alkohol und wurde am folgenden Tage, also am 14., und zwar 23\%/4 Stunden nach dieser Alkoholzufuhr, in einem dritten Versuch in den Respirationskasten gebracht, in dem er 24 Stunden blieb. Die für die reduzierenden Stoffe ermittelte Zahl entsprach 0,061 cem Alkohol, stimmt also befriedigend mit den bei alkoholfreiem Regime ermittelten Daten überein. Somit wird nach 24 Stunden nach der Aufnahme kein Alkohol mehr unverbrannt durch die Atmung ausgeschieden. Auch der Harn wurde bei diesem Versuch quantitativ gewonnen und das Destillat auf reduzierende Stoffe untersucht. Die Bestimmung ergab, dass solche Substanzen im Urin nicht enthalten waren. Also auch durch die Nieren wird 24 Stunden nach der Aufnahme kein Alkohol mehr sezerniert. Wir haben noch mehrfach die Destillate des innerhalb 24-28 Stunden nach der Alkoholzufuhr ausgeschiedenen Urins auf reduzierende Stoffe untersucht, und $\mathrm{zwar}$ stets mit dem gleichen negativen Befund.

\section{Versuch am 18./19. April 1910 .}

Das Tier wog $8,15 \mathrm{~kg}$ und erhielt $29,49 \mathrm{ccm}$, also pro Körperkilogramm 3,62 cem Alkohol. Der Hund blieb 21 Stunden im Apparat. Die ausgeschiedene Alkoholmenge betrug: im Harn 1,150 ccm, in der Atmung $1,862 \mathrm{ccm}=$ Sa. $3,012 \mathrm{ccm}=10,2 \%$.

Wie oben bemerkt, war etwas Harn in den Apparat gelangt, und wir haben infolgedessen den in besonderen Versuchen quantitativ bestimmten Harnalkohol von der gesamten ausgeschiedenen Alkoholmenge (Harn und Atmung) subtrahiert (s. Seite 92). Nach der Durchführung dieser Berechnung ergaben sich für den vorliegenden Versuch folgende Werte: im Harn $1,575 \mathrm{ccm}=5,3 \%$, in der Atmung 1,437 $\mathrm{cm}=4,9 \%=$ Sa. 3,012 ccm Alkohol $=10,2 \%$.

In Prozenten der Gesamtausscheidung: im Harn $=52,4$, in der Atmung $=47,6$.

\section{Versuch am 19./20. April 1910.}

In diesem Versuch wurde ausserhalb des Respirationsapparates der Alkoholgehalt des Harnes quantitativ bestimmt. Der Hund wog vor Beginn des Versuches $8,20 \mathrm{~kg}$ und erhielt insgesamt 29,29 $\mathrm{cm}$ 
resp. $3,68 \mathrm{ccm}$ Alkohol pro Körperkilogramm. Versuchsdauer 22 Stunden. Der Harn enthielt 1,190 ecm Alkohol $=4,06 \%$ der Zufuhr.

\section{Versuch am 21./22. April 1910.}

Der Hund wog $8,650 \mathrm{~kg}$ und erhielt $29,49 \mathrm{ccm}$, resp. pro Körperkilogramm 3,41 ccm Alkohol: Versuchsdauer 21 Stunden. Auch bei diesem Versuch war die Trennung von Harnalkohol und Alkohol der Atmung: nicht möglich, weil eine erhebliche Menge Harn in den Apparat entleert worden war. Der in die Harnflasche gelaufene und ferner der durch Katheterisieren gewonnene Harn enthielt zusammen 0,700 cem Alkohol, während wir in den Bichromatvorlagen für den Alkohol in der Atmung und den im Apparat verbliebenen Harn 1,814 ccm fanden. Die gesamte in Harn und Atmung ausgeschiedene Alkoholmenge betrug somit $0,700+1,814=2,514 \mathrm{ccm}$, entsprechend $8,5 \%$ der Einnahme.

Nach Ausführung der Korrektur (s. S. 92) ergibt sich für den Harn 1,575 ccm $==5,3 \%$, für die Atmung $0,939 \mathrm{ccm}=3,1 \%$ $=$ Sa. $2,514 \mathrm{ccm}$ Alkohol $=8,5^{\circ}$ o.

In Prozenten der Gesamtausscheidung: im Harn 62,7, in der Atmung 37, 1.

Vom 22./23. April ab erhielt der Hund an allen Tagen zwischen den einzelnen Versuchstagen zwecks Gewöbnung an Alkohol pro die ca. $20 \mathrm{ccm} 90 \%$ igen Alkohol in das Futter gemischt, das stets sofort restlos verzehrt wurde.

\section{Versuch am 23./24. April 1910.}

Der Hund wog $8,85 \mathrm{~kg}$ und erbielt $29,49 \mathrm{ccm}$, resp. $3,33 \mathrm{ccm}$ Alkohol pro Körperkilogramm. Versuchsdauer 22 Stunden. Der Harn gelangte auch hier teilweise in den Apparat. In dem nach aussen gelangten Harn wurden gefunden $1,110 \mathrm{ccm}$, in den Bichromatvorlagen $1,325 \mathrm{ccm}=$ Sa: $2,435 \mathrm{~cm}$ Alkohol $=8,3 \%$.

Nach Ausführung der Korrektur (s. S. 92) ergibt sich: für den Harn $1,575 \mathrm{ccm}=5,34 \%$, für die Atmung $0,860 \mathrm{~cm}=2,92 \%$ $=$ Sa. $2,435 \mathrm{ccm}=8,3 \%$, resp. in Prozenten der Gesamtausscheidung: im Harn $64,7 \%$, in der Atmung 35,3\%.

\section{Versuch am 25./26. April 1910.}

Der Hund wog $8,97 \mathrm{~kg}$ und erhielt $29,49 \mathrm{ccm}$, resp. pro Körperkilogramm 3,29 cem Alkohol. Versuchsdauer 21 Stunden. Bei diesem Versuch wurde sämtlicher Harn ausserhalb des Apparates gewonnen. 
Wir fanden: im Harn $1,720 \mathrm{ccm}=5,8 \%$, in der Atmung $0,912 \mathrm{ccm}$ $=3,1 \%=$ Sa. $2,632 \mathrm{ccm}$ Alkohol $=8,9 \%$.

In Prozenten der Gesamtausseheidung: im Harn $65,3 \%$, in der Atmung $34,7 \%$.

\section{Versuch am 28./29. April 1910.}

Der Hund"wog 8,900 kg und erhielt 29,49 cem, resp. pro Körperkilogramm 3,31 cem Alkohol. Bei diesem Versuch wurde, wie oben besprochen, nur der Harnalkohol, und zwar ausserhalb des Respirationsapparates, bestimmt.

Wir fanden: $1,571 \mathrm{cem}$ Alkohol $=5,3 \%$ der Zufuhr im Harn.

\section{Versuch am 27. 28. Mai 1910.}

Bevor dieser Versuch zur Ausführung gelangte, haben wir an diesem Hunde eine Versuchsreihe (III) mit denselben Alkoholmengen in konzentrierterer Form (50\%ig) durchgeführt, um den Einfluss des Flüssigkeitsvolums auf die Alkoholausscheidung zu studieren. Nach Abschluss der Reihe III wurde der zu dieser Versuchsreihe gehörende 10. Versuch mit 29,49 cem Alkohol in 9,84\%iger Lösung ausgeführt. Das Tier wog $9,80 \mathrm{~kg}$ und erhielt somit pro Körperkilogramm 3,01 ccm Alkohol.

Wir fanden: im Harn $1,730 \mathrm{ccm}=5,9 \%$, in der Atmung $1,032 \mathrm{cem}=3,5 \%=$ Sa. 2,762 cem Alkohol $=9,4 \%$ der Zufuhr.

In Prozenten der Gesamtausscheidung: im Harn 62,6, in der Atmung 37,4 .

Die folgende Tabelle 2 (S. 96) ermöglicht eine Übersicht über die in dieser Reihe I gewonnenen Resultate.

Wir ersehen aus der nachstehenden Tabelle, dass nach der sehr starken Alkoholzufuhr von ca. 3,2 cem pro Körperkilogramm in einer Dosis und in 9,84\% iger Lösung, also in einer Konzentration, die etwa dem Alkoholgehalt vieler Weine entspricht, eine sehr erhebliche Alkoholmenge in Harn und Atmung ausgeschieden wird. Der höchste Wert, nämlich $11,6 \%$, wurde beim ersten Versuch gefunden, als der Hund wahrscheinlich zum erstenmal in seinem Leben Alkohol erhielt; den geringsten Wert, nämlich $8,3 \%$ der Zufuhr, ermittelten wir beim siebenten Versuch; bei den folgenden Versuchen 8 und 9 steigen die betreffenden Werte wieder etwas an, und zwar auf 8,9 und $9,4 \%$. Die höchsten Werte, welche bei den beiden ersten Versuchen gefunden wurden, sind auf die vermehrte Alkoholausscheidung durch die Atmung zurückzuführen, während die Alkoholsekretion durch 
Wilhelm Völtz und August Baudrexel:

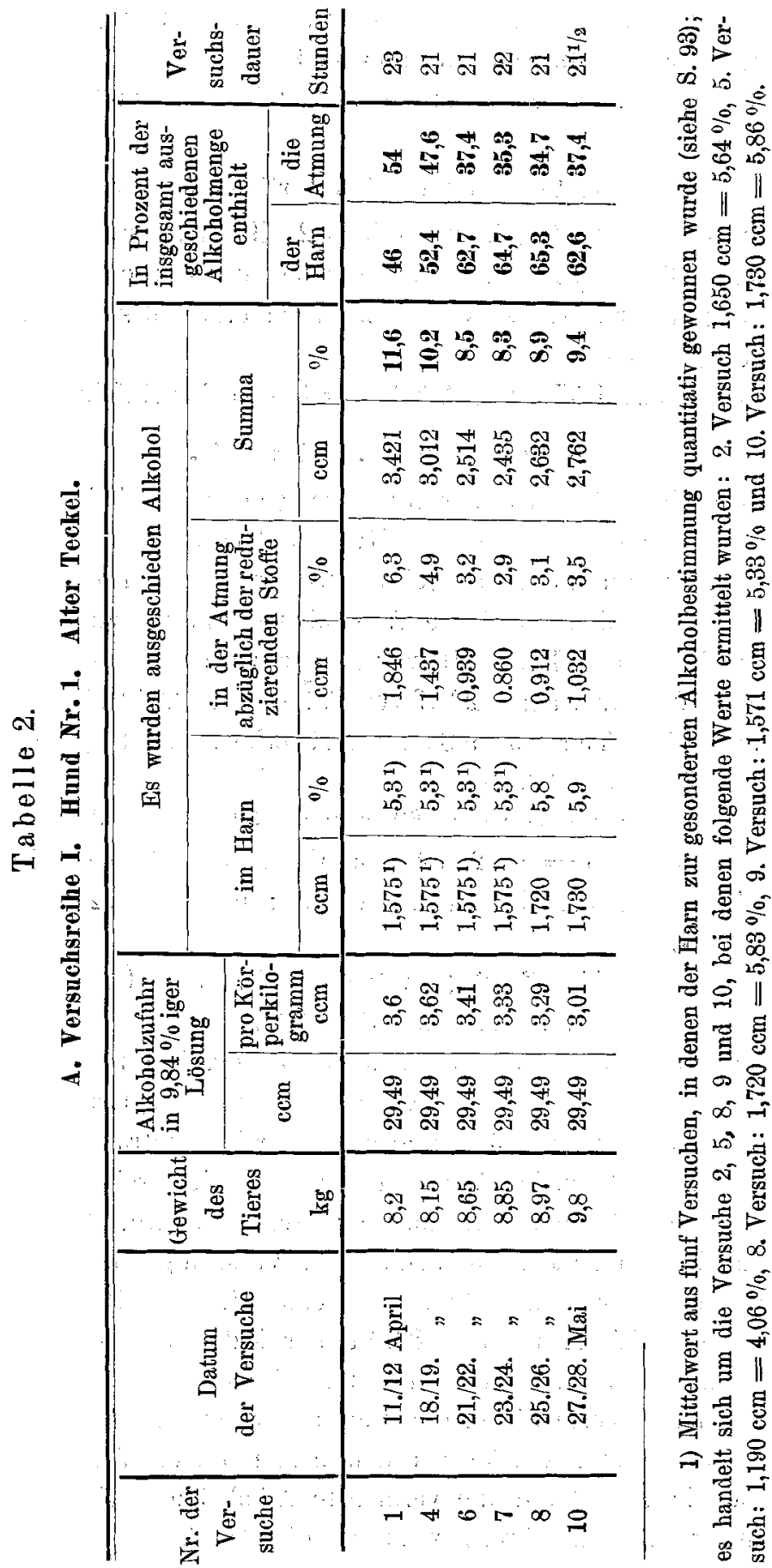


die Nieren annähernd konstant bleibt. Zu Beginn der Versuche war die Reaktion auf die toxischen Alkoholgaben natürlich am stärksten, das Tier heulte länger als bei den späteren Versuchen, die Lungenatmung erfolgte also forcierter, und daher wurde auch zunächst mehr Wasser- und Alkoholdampf ausgeschieden als später.

\section{Versuche an drei jungen Hunden desselben Wurfes Nr. 2, 3 and 4. \\ $\alpha$. 3 Versuche an dem jungen Hund Nr. 2. \\ 1. Versuch.}

Der ältere Hund hatte sehr grosse Alkoholg̣aben erhalten, nämlich ca. $3,2 \mathrm{ccm}$ pro Körperkilogramm in $9,84 \%$ iger Lösung.

Der junge Hund erhielt Alkohol der gleichen Konzentration, jedoch etwa nur 1/3 der Menge, nämlich ca. 1 cem pro Körperkilogramm. Der erste Versuch von 21 stündiger Dauer wurde am 8./9. April 1910 angestellt. ca. 1/2 Stunde nach der Alkoholzufuhr mittels Schlundsonde schlief das Tier im Respirationsapparat ein. Die quantitative Alkoholbestimmung in der Atmung gelang njeht. Der Hund wog $4,260 \mathrm{~kg}$ und erhielt $4,92 \mathrm{ccm}=1,15 \mathrm{ccm}$ Alkohol pro Körperkilogramm. Im Harn wurden gefunden 0,075 cem resp. 1,5\% der Zufuhr. Bei den ersten drei Versuchen dieser Reihe wurden allerdings sehr geringe Harnmengen in den Apparat entleert; bei den späteren wurde der Harn dagegen stets restlos nach aussen geleitet.

\section{Versuch am 12./13. April 1910.}

Der Hund wog $4,32 \mathrm{~kg}$ und erhielt $4,92 \mathrm{cem}$ resp. pro Körperkilogramm 1,14 ccm Alkohol. Das Tier heulte einige Zeit nach der Alkoholzufuhr ${ }^{1}$ ). Versuchsdauer 20 Stunden.

Es wurden gefunden: im Harn $0,065 \mathrm{ccm}=1,3 \%$; in der Atmung $0,147 \mathrm{ccm}=3,0 \%=$ Sa. $0,212 \mathrm{ccm}=4,3 \%$ Alkohol.

In Prozenten der Gesamtausscheidung: im Harn 30,6\%; in der Atmung $69,4 \%$.

3. Versuch am 15.16. April 1910.

Gewicht des Tieres $4,57 \mathrm{~kg}$, Alkoholzufuhr 4,92 ecm resp. 1,08 ecm pro Körperkilogramm. Das Tier schläft bald nach der Alkoholaufnahme ein. Versuchsdauer 20 Stunden.

1) Siehe die Anmerkung auf S. 107. 
Es wurden gefunden: im Harn $0,085 \mathrm{cem}=1,7 \%$; in der Atmung $0,078 \mathrm{~cm}=1,6 \%=$ Sa. $0,163 \mathrm{~cm}=3,3 \%$ Alkohol.

In Prozenten der Gesamtausseheidung: im Harn $52,2 \%$; in der Atmung $47,8 \%$.

$\beta$. 3 Versuche an einem jungen Hund Nr. 3 desselben Wurfes,

der ebenfalls bei dem ersten Versuch (Nr. 4) zum erstenmal in seinem Lehen Alkohol erhielt.

\section{Versuch am 25.26. Mai 1910.}

Versuchsdauer 22 Stunden. Der Hund wog $6,52 \mathrm{~kg}$. und erhielt 4,92 cem resp. pro Körperkilogramm $0,75 \mathrm{cem}$ Alkohol. Die Gewinnung des Harnes gelang vollständig. Der Hund heulte einige Minuten nach der Alkoholzufuhr kurze Zeit und dann noch wiederholt in kurzen Zwischenräumen bis 3 Stunden nach der Aufnahme von Alkohol.

Es wurden gefunden: im Harn $0,041 \mathrm{cem}=0,8 \%$; in der Atmung $0,147 \mathrm{ccm}=3,0 \%=$ Sa. $0,188 \mathrm{~cm}=3,8 \%$ Alkohol.

In Prozenten der Gesamtausscheidung: im Harn $21,8 \%$; in der Atmung 78,2\%.

\section{Versuch am 28.29. Mai 1910.}

Versuchsdauer 23 Stunden. Der Hund wog $6,55 \mathrm{~kg}$ und erhielt $7,48 \mathrm{ccm}$ resp. pro Körperkilogramm 1,15 cem Alkohol. Das Tier verhielt sich während des Versuches ganz ruhig.

Es wurden gefunden: im Harn $0,206 \mathrm{ccm}=2,8 \%$; in der Atmung $0,078 \mathrm{~cm}=1,0 \%=$ Sa. $0,284 \mathrm{cem}=3,8 \%$ Alkohol.

In Prozenten der Gesamtausscheidung: im Harn 72,5\% in der Atmung 27,5\%.

\section{Versuch am 31. Mai/1. Juni 1910.}

Versuchsdauer 22 Stunden. Der Hund wog $6,50 \mathrm{~kg}$ und erhielt 7,48 cem resp. pro Körperkilogramm $1,15 \mathrm{~cm}$ Alkohol.

Es wurden gefunden: im Harn $0,121 \mathrm{ccm}=1,6 \%$; in der Atmung $0,112 \mathrm{ccm}=1,5 \%=$ Sa. $0,233 \mathrm{ccm}=3,1 \%$ Alkohol.

In Prozenten der Gesamtausscheidung: im Harn $51,9 \%$; in der Atmung 48,1\%. 
y. Ein Versuch an einem dritten Hund Nr. 4 desselhen Wurfes, der ebenfalls zum erstenmal Alkohol erhielt.

\section{Versuch 7, am 96./27. Mai 1910.}

Versuchsdauer 23 Stunden. Der Hund wog $8,62 \mathrm{~kg}$ und erhielt $9,94 \mathrm{ccm}$ resp. pro Körperkilogramm 1,15 cem Alkohol. Das Tier verhielt sich vollständig ruhig.

Es wurden gefunden: im Harn $0,142 \mathrm{ccm}=1,4 \%$; in der Atmung $0,117 \mathrm{ccm}=1,2 \%=$ Sa. 0,259 $\mathrm{cm}=2,6 \%$ Alkohol.

In Prozenten der Gesamtausscheidung: im Harn 54,8\%; in der Atmung $45,2 \%$.

Die folgende Tabelle 3 (S. 100) bringt eine Übersicht über die in dieser Versuchsreihe gewonnenen Resultate.

Aus diesen Resultaten ergeben sich folgende Schlüsse:

Alkoholdosen von 0,75-1,15 cem pro Körperkilogramm bewirkten bei dèn drei jungen Hunden also eine Gesamtausscheidung von 2,6-4,3\% der aufgenommenen Alkoholmenge, also etwa nur $1 / 3$ derjenigen Quantität, welche der ältere Teckel nach der dreifachen Dosis von 3,01-3,6 cem pro Kilogramm ausgeschieden hatte. Wir sehen also, dass die Quantität des aufgenommenen Alkohols von grossem Einfluss ist auf die Alkoholausscheidung in Harn und Atmung. Was nun das Verbältnis des Harnalkobols zu dem Alkohol der Atmung: anbelangt, so finden wir sowohl bei dem älteren Hunde als auch bei den jungen Tieren bei den ersten Versuchen die relativ höchsten Werte für den Alkoholgehalt in der Atmung. Diese Befunde finden ihre Erklärung in der-Tatsache, dass bei den nicht an Alkohol gewöhnten Tieren der Alkohol stärkere zentrale Wirkungen und somit stärkere Reaktionen des Organismus zur Folge hat, als bei solchen Tieren, die an Alkoholaufnahme mehr gewöhnt sind. Diese Reaktionen äusserten sich insbesondere in einem längere oder kürzere Zeit anhaltenden Heulen, das naturgemäss eine verstärkte Atmung und somit vermehrte Wasserdampf- und Alhoholabgabe an die ausgeatmete Luft zur Folge hatte.

Der Befund, dass der Hund Nr. 4 nach der ersten Alkoholdosis, die er erhieit, etwas weniger Alkohol in der Atmung als im Harn ausschied, steht nicht in Widerspruch zu den übrigen Befunden, denn es handelt sich bei diesem Hunde um das grösste und kräftigste 
Wilhelm Völtz und August Baudrexel:

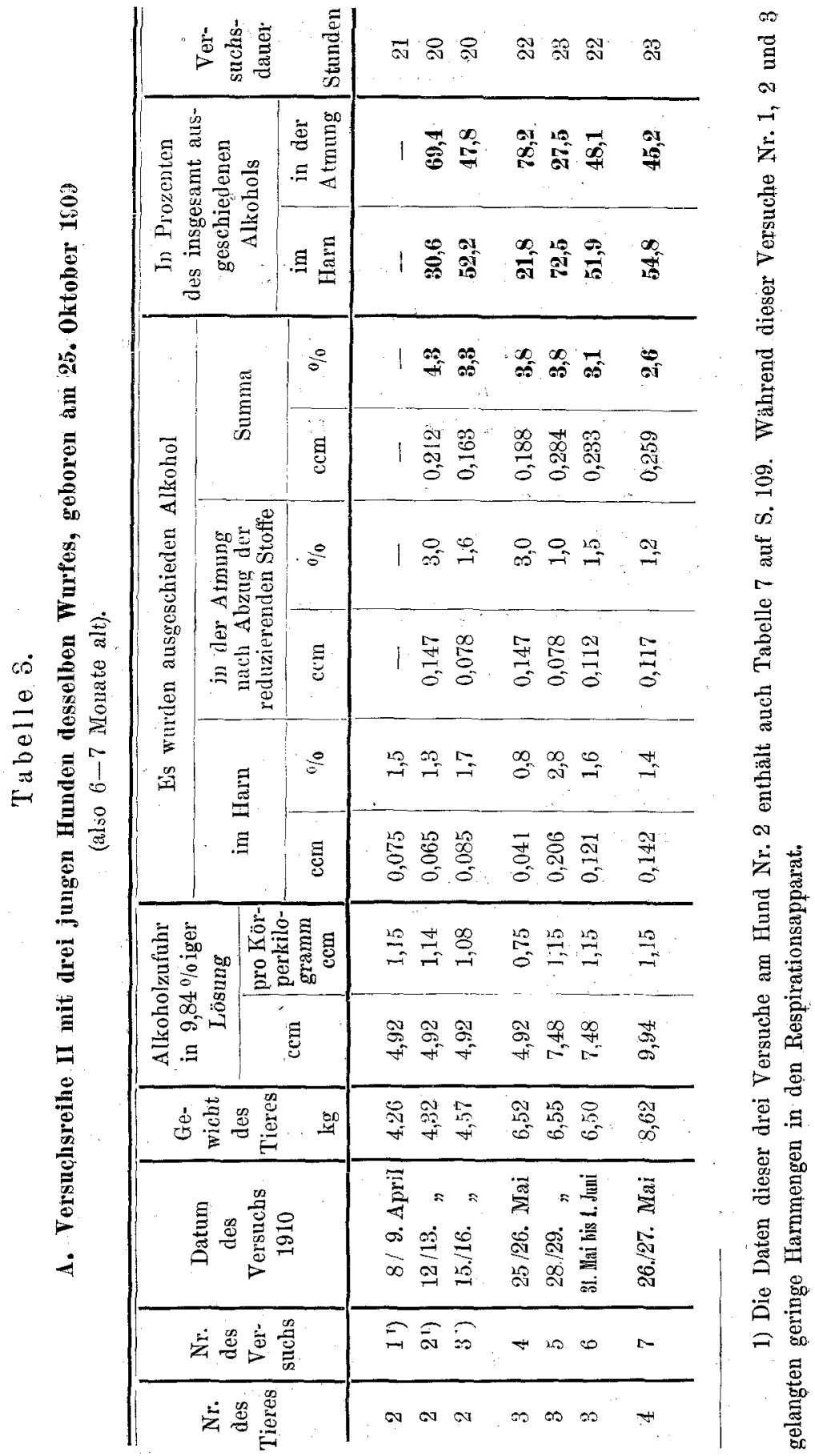


Tier des ganzen Wurfes, das also weniger durch die Alkoholgabe alteriert wurde als die übrigen, und das sich auch nach der ersten Alkoholzufuhr vollständig ruhig verbielt.

\section{B. Einfluss der Gewöhnung auf die vom Organismus} ausgeschiedenen Alkoholmengen.

Zu dieser Frage liefert bereits die Versuchsperiode unter A (siehe die Tabelle 2 auf Seite 96 ) an dem alten Teckel einiges Material. Der Hund hatte ca. $3,2 \mathrm{~g}$ Alkohol pro Körperkilogramm in einer Portion, also toxische Dosen, erhalten. Die zunächst in Harn und Atmung ausgeschiedene Alkoholmenge von 11,6\% der Zufuhr sank unter dem Einfluss der Gewöhnung bis auf $8,3 \%$. Dieser Wert konnte auch, nachdem der Hund längere Zeit an gleiche Alkoholdosen, die in konzentrierterer Form (50\% ig) gegeben wurden, gewöhnt war und hierauf dieselbe Alkoholmenge wieder in 9,84\% iger Lösung erhielt, nicht mehr unterschritten werden; wir fanden im Gegenteil wieder einen höheren Wert (9,4\% der Zufuhr) in den Ausscheidungsprodukten. Die Gewöhnung hatte also unter den gewählten Versuchsbedingungen, d. h. bei einer Zufuhr von $3,2 \mathrm{ccm}$ Alkohol pro Körperkilogramm in einer Dosis und in 9,84\% iger Lösung, zwar eine erhebliche, aber keine sehr grosse Verminderung der Ausscheidung von Alkohol durch den Tierkörper bewirken können.

- Wir haben nun an demselben Tier bei Zufuhr der gleichen Alkoholmenge, die dagegen in konzentrierterer Form (ca. 50\% gegeben wurde, den Einfluss der Gewöhnung in sieben Versuchen, die sich über einen Zeitraum von etwa 1 Monat erstreckten, studiert. An' den versuchsfreien Zwischentagen erhieit der Hund ebenfalls regelmässig Alkohol, und zwar etwa zwei Drittel der an den Versuchstagen gereichten Menge.

Zur Erleichterung der Übersicht über die Versuchszeit geben wir auf S. 102 Tabelle 4.

Die Trennung des Alkohols im Harn von demjenigen in der Atmung gelang stets vollständig.

Wir lassen nunmehr die detaillierten Angaben über die einzelnen Versuche folgen und bemerken, dass wir die reduzierenden Substanzen von dem in der Atmung ermittelten Alkohol bereits subtrahiert haben. 
Tabelle 4.

Übersicht über die Versuchsreihe an dem alten Hund Nr. 1.

\begin{tabular}{|c|c|c|c|c|}
\hline $\begin{array}{c}\text { Datum } \\
1910\end{array}$ & $\begin{array}{c}\text { Versuch } \\
\text { Nr. }\end{array}$ & $\begin{array}{c}\text { Alkohol- } \\
\text { zufuhr in } \\
\text { ca. } 50 \% \text { iger } \\
\text { Lösung } \\
\text { ccm }\end{array}$ & & $\begin{array}{l}\text { Versuchs- } \\
\text { dauer } \\
\text { Stunden }\end{array}$ \\
\hline 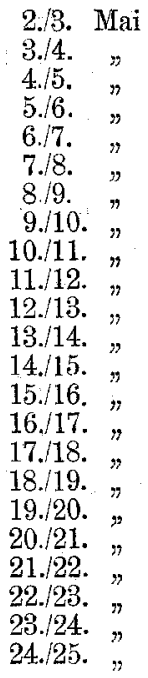 & $\begin{array}{l}1 \\
2 \\
- \\
- \\
- \\
-3 \\
- \\
- \\
- \\
- \\
\frac{-}{4} \\
\frac{-}{5} \\
\frac{5}{6} \\
\frac{7}{7}\end{array}$ & $\begin{array}{l}29,74 \\
20 \\
29,74 \\
20 \\
20 \\
20 \\
20 \\
20 \\
29,74 \\
20 \\
20 \\
20 \\
20 \\
20 \\
20 \\
20 \\
29,74 \\
20 \\
29,74 \\
20 \\
29,74 \\
20 \\
29,74\end{array}$ & $\begin{array}{l}\text { An den sieben } \\
\text { Versuchstagen } \\
\text { wurde der Alkohol } \\
\text { regelmässig in Harn. } \\
\text { und Atmung be- } \\
\text { stimmt }\end{array}$ & $\begin{array}{c}22^{1 / 2} \\
\overline{-} \\
23^{3 / 4} \\
\overline{-} \\
\overline{-} \\
23^{3 / 4} \\
\overline{-} \\
\overline{-} \\
\overline{-} \\
\overline{-} \\
23^{1 / 4} \\
23^{-} \\
24\end{array}$ \\
\hline
\end{tabular}

\section{Versuch am 2./3. Mai 1910.}

Der Hund wog $8,75 \mathrm{~kg}$ und erhielt $29,74 \mathrm{cem}$ resp. pro Körperkilogramm $3,38 \mathrm{cem}$ Alkohol. Versuchsdauer 221/2 Stunden. Einige Stunden nach der Alkoholzufuhr winselte der Hund kurze Zeit.

Der Harn enthielt: $0,161 \mathrm{ccm}=0,5 \%$; in der Atmung: $1,031 \mathrm{ccm}=3,5 \%=$ Sa. $1,192 \mathrm{cem}$ Alkohol $=4,0 \%$, resp. in Prozenten der Gesamtausscheidung: im Harn $13,5 \%$; in der Atmung 86,5\%.

\section{Versuch am 4./5. Mai 1910 .}

Der Hund wog $9,00 \mathrm{~kg}$ und erhielt $29,74 \mathrm{cem}$ resp. pro Körperkilogramm $3,3 \mathrm{ccm}$ Alkohol. Versuchsdauer 23/4. Stunden. Das Tier verhielt sich rubig.

Der Harn enthielt: $0,324 \mathrm{cem}=1,1 \%$; in der Atmung: $0,839 \mathrm{ccm}=2,8 \%=$ Sa. $1,163 \mathrm{cem}$ Alkohol $=3,9 \%$ résp. in Prozentèn der Gesamtausscheidung; im Harn $27,8 \%$; in der Atmung 72,2\%. 
3. Versuch am 10.11. Mai 1910.

Das Tier wog $9,8 \mathrm{~kg}$ und erhielt $29,74 \mathrm{cem}$ resp. pro Körperkilogramm $3,0 \mathrm{ccm}$ Alkohol. Versuchsdauer $23^{3 / 4}$ Stunden. Zwei Stunden nach der Alkoholaufnahme heulte der Hund etwas.

Der Harn enthielt: $0,455 \mathrm{cem}=1,5 \%$; in der Atmung: $0,656 \mathrm{cem}=2,2 \%=$ Sa. $1,111 \mathrm{cem}$ Alkohol $=3,7 \%$, resp. in Prozenten der Gesamtausscheidung: im Harn 40,9\%; in der Atmung 59,1\%.

\section{Versuch am 18./19. Mai 1910 .}

Das Tier wog $10,1 \mathrm{~kg}$ und erhielt $29,74 \mathrm{cem}$ resp. pro Körperkilogramm 2,9 ccm Alkohol. Versuchsdauer 23 Stunden. Der Hund verhielt sich ruhig.

Der Harn enthielt: $0,456 \mathrm{ccm}=1,5 \%$; in der Atmung: $0,416 \mathrm{cem}=1,4 \%=$ Sa. $0,872 \mathrm{ecm}$ Alkohol $=2,9 \%$ resp. in Prozenten der Gesamtausscheidung: im Harn 52,3\%, in der Atmung 47,7\%.

\section{Versuch am 20.21. Mai 1910 .}

Der Hund wog $10,20 \mathrm{~kg}$ und erhielt $29,74 \mathrm{cem}$ resp. pro Körperkilogramm 2,9 ccm Alkohol. Versuchsdauer 231/4 Stunden. Einige Zeit nach der Alkoholzufuhr heulte der Hund etwas.

Der Harn enthielt: $0,405 \mathrm{cem}=1,4 \%$; in der Atmung: $0,486 \mathrm{~cm}=1,6 \%=$ Sa. 0,891 cem Alkohol $=3,0 \%$. ' In Prozenten der Gesamtausscheidung: im Harn $45,5 \%$; in der Atmung $54,5 \%$.

\section{Versuch am 29.29. Mai 1910.}

Der Hund wog $9,9 \mathrm{~kg}$ und erhielt $29,74 \mathrm{ccm}$ resp. pro Körperkilogramm 3,0 cem Alkohol. Versuchsdauer 23 Stunden. Der Hund verhielt sich ruhig.

Der Harn enthielt: $0,188 \mathrm{cem}=0,6 \%$; in der Atmung: $0,634 \mathrm{ccm}=2,1 \%=$ Sa. $0,822 \mathrm{ccm}=2,7 \%$. In Prozenten der Gesamtausscheidung: im Harn $22,9 \%$; in der Atmung $77,1 \%$.

\section{Versuch am 24./25. Mai 1910 .}

Der Hund wog $9,55 \mathrm{~kg}$ und erhielt $29,74 \mathrm{ccm}$ resp. pro Körperkilogramm 3,1 cem Alkohol. Versuchsdauer 24 Stunden. Der Hund verhielt sich ruhig.

Der Harn enthielt: $0,204 \mathrm{cem}=0,7 \%$; in der Atmung: $0,633 \mathrm{ccm}=2,1 \%=$ Sa. $0,837 \mathrm{ccm}$ Alkohol $=2,8 \%$. In 
Prozenten der Gesamtausscheidung: im Harn 24,4\%; in der Atmung 75,6\%.

In der folgenden Tabelle 5 haben wir die Resultate dieser sieben Versuche zusammengestellt.

Tabelle 5 .

Versuchsreihe an dem alten Hund Nr. 1.

\begin{tabular}{|c|c|c|c|c|c|c|c|c|c|c|c|c|c|}
\hline \multirow{5}{*}{ 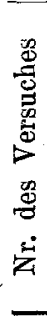 } & \multirow{5}{*}{$\begin{array}{c}\text { Datum des } \\
\text { Versuches } \\
1910\end{array}$} & \multirow{5}{*}{ 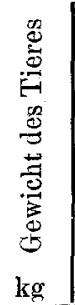 } & \multirow{2}{*}{\multicolumn{2}{|c|}{$\begin{array}{l}\text { Alkohol- } \\
\text { zufuhr in } \\
\text { ca. } 50 \% \text { iger } \\
\text { Lossung }\end{array}$}} & \multicolumn{6}{|c|}{$\begin{array}{l}\text { Es wurden ausgeschieden } \\
\text { Alkohol }\end{array}$} & \multirow{3}{*}{\multicolumn{2}{|c|}{$\begin{array}{l}\text { In Prozent } \\
\text { des insgesamt } \\
\text { ans- } \\
\text { geschiedenen } \\
\text { Alkohols }\end{array}$}} & \multirow{5}{*}{ 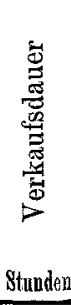 } \\
\hline & & & & & \multirow{3}{*}{\multicolumn{2}{|c|}{ im Harn }} & \multirow{3}{*}{\multicolumn{2}{|c|}{$\begin{array}{c}\text { in der } \\
\text { Atmung } \\
\text { nach Ab- } \\
\text { zug d.redu- } \\
\text { zierenden } \\
\text { Stoffe } \\
\end{array}$}} & & & & \\
\hline & & & \multirow{3}{*}{$\mathrm{ecm}$} & \multirow{3}{*}{ 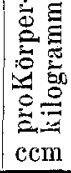 } & & & & & & & & & \\
\hline & & & & & & & & & & & & & \\
\hline & & & & & $\mathrm{ccm}$ & $\%$ & $\mathrm{ccm}$ & $1 \%$ & $\mathrm{ccm}$ & $\%$ & & & \\
\hline & 2 & & & & & 0,5 & & & & & & & \\
\hline & & 9,0 & & & & & & & & & & & \\
\hline & & & & 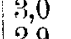 & & 1,5 & & & & & & & \\
\hline & & $\begin{array}{l}10,1 \\
1020\end{array}$ & & 2,8 & & 1. & & & & & & & \\
\hline & & 9,9 & 29 & 3.0 & & 06 & & 2 & 0,822 & & & & \\
\hline & & 9 & & & & 0,7 & & 2,1 & 0,837 & & & & 24 \\
\hline
\end{tabular}

Aus dieser Versuchsreihe ergeben sich bezüglich des Einflusses der Gewöhnung auf die Ausscheidung des Alkohols in Harn und Atmung folgende Schlüsse:

Nach der Zufuhr von 2,9-3,4 cem Alkohol pro Körperkilogramm in $50 \%$ iger Lösung gelangen zunächst insgesamt $4 \%$ zur Ausscheidung; dieser Wert sinkt im Verlauf von drei Wochen kontinuierlich um rund ein Drittel $a b$ und kann auch bei weiterer Gewöhnung nicht mehr unterschritten werden. Es ist bemerkenswert, dass bei dem, kurze Zeit an stark verdünnten Alkohol gewöhuten, Hund durch weitere Gewöhnung keine höhere Verwertung des Alkohols mebr erzielt werden kann (A. Versucbsreihe I, Tab. 2 S. 96). Nach der Verabreichung derselben Alkoholmenge in stärkerer Konzentration an dasselbe an stark verdünnten Alkohol gewöhnte Tier sinkt dagegen die zunächst ausgeschiedene und von vornherein geringere Alkoholmenge unter dem Einfluss weiterer Gewöhnung noch um ein weiteres Drittel ab. Die gleiche Alkoholmenge in konzentrierterer Lösung bleibt hier infolge geringerer Diurese und infolge geringerer Wasser- und Alkoholdampfabgabe durch die Lungen länger in den 
Geweben und kann daher zu einem höheren Prozentsatz verwertet werden.

Was das Verbältnis des in der Atmung ausgeschiedenen Alkohols zu dem durch die Nieren sezernierten Alkohol betrifft, so gelangten mit einer einzigen Ausnahme (4. Versuch) grössere Mengen durch die Atmung zur Ausscheidung, und zwar am ersten Tage das Maximum $(86,5 \%)$.

Nach Verabreichung derselben Alkoholmenge in stärkerer Verdünnung $(9,84 \%)$ A. Versuchsreibe 1 (Tabelle 2 S. 96) wurde von demselben Tier nur am ersten Tage eine etwas grössere Alkoholmenge durch die Atmung ausgeschieden; später war die Atmung weniger forciert und die ausgeatmete Alkoholmenge daher geringer, während die durch die Nieren sezernierten Alkoholmengen annähernd konstant blieben.

In Versuchen an Menschen fanden Atwater und Benedict (1. c.) etwa die neunfache Menge des im Harn ermittelten Alkohols in der Atmung. Wir können hieraus sehr gut erkennen, welche bedeutsame Rolle die Hautatmung beim Menschen spielt, während die Wärmeregulation beim Hunde so gut wie ausschliesslich dureh die Maulhöhle und die Nase erfolgt, also eine Wasserdampfabgabe und somit auch eine Ausscheidung von Alkohol durch die Haut fast gar nicht in Frage kommt.

Versuchsreihe an dem jungen Hund Nr. 2.

Das Tier wog bei Beginn der Versuche $4,26 \mathrm{~kg}$. Innerhalb eines Zeitraums von ca. 5 Wochen, und zwar vom 8. April bis zum 14. Mai, wurden 11 Versuche durchgeführt. An den Zwischentagen, welche die ersten drei Versuche trennen, erhielt der Hund keinen Alkohol. Vom 18. April ab wurden an sämtlichen Tagen, an denen das Tier sich nicht im Versuch befand, $50 \mathrm{ccm}$ einer $9,84 \%$ igen Alkohollösung $=4,9 \mathrm{ccm}$ Alkohol resp. pro Körperkilogramm ca. 1 cem mit dem Futter aufgenommen. An den 11 Versuchstagen erhielt der Hund ebenfalls die gleiche Menge Alkohol mittels Schiundsonde, und zwar nach der Fütterung.

Die Abgrenzung des. Harues erfolgte nach Abschluss jedes Versuches regelmässig, und zwar nach der von $Z$ untz vorgeschlagenen Methode (I. c.). Der so gewonnene Harn wurde mit dem während des Versuches gesammelten Harn vereinigt und zur Alkoholbestimmung destilliert. Während der ersten direi Versuchstage wurden allerdings 
sehr geringe Harnmengen in den Respirationsapparat entleert; bei den späteren Versuchen gelangte der Harn restlos aus dem Apparat in die zur Aufnahme bestimmte Flasche.

Die Übersicht über die an den Versuchstagen und den Zwischentagen verabreichten Alkoholmengen enthält die folgende Tabelle.

\section{Tabelle 6.}

Die Alkoholbestimmungen wurōen mit Ausnahme des. 7. Versuches (29./30. April) stets in Harn und Atmung ausgeführt. Der 9. Versuch misslang, weil der Hund nac̈h etwa 4 stündigem Aufenthalt im Respirationsapparat das Futter zum Teil erbrach.

Übersicht über die Versuchsreihe an dem jungen Hund Nr. 2.

\begin{tabular}{c|c|c|c|c}
\hline & \\
\hline 1910 & $\begin{array}{c}\text { Versuch } \\
\text { Nr. }\end{array}$ & $\begin{array}{c}\text { Alkoholzufuhr } \\
\text { in 9,84\% \% iger } \\
\text { Lösung } \\
\text { ccm }\end{array}$ & $\begin{array}{c}\text { Versuchs- } \\
\text { dauer } \\
\text { Stunden }\end{array}$ & Bemerkungen \\
\hline 8./9. April & $\left.1^{1}\right)$ & 4,92 & 21 &
\end{tabular}

Vom 9. April bis 12. April erhält der Hund keinen Alkohol.
12./13. April
$2^{1)}$
4,92
20

Vom 13. April bis 15. April erhält der Hund keinen Alkohol.
15./16. April
$\left.3^{1}\right)$
4,92
20

Vom 16. April bis 18. April erhält der Hund keinen Alkohol.

18./19. April

$19 . / 20$.

20./21.

21.22.

$22.123 . "$

23./24. "

$24 . / 25$.

$25 / 26$

$26 . / 27$.

$27 . / 28$.

$28 . / 29$.

$29 . / 30$.

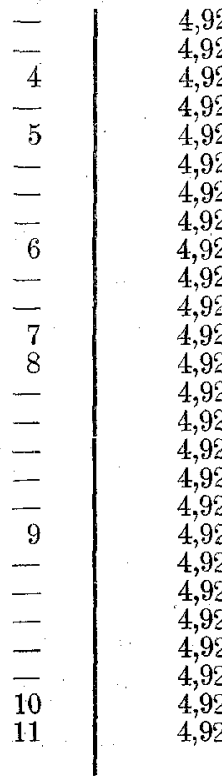

4,92
4,92
4,92
4,92
4,92
4,92
4,92
4,92
4,92
4,92
4,92
4,92
4,92
4,92
4,92
4,92
4,92
4,92
4,92
4,92
4,92
4,92
4,92
4,92
4,92
4,92

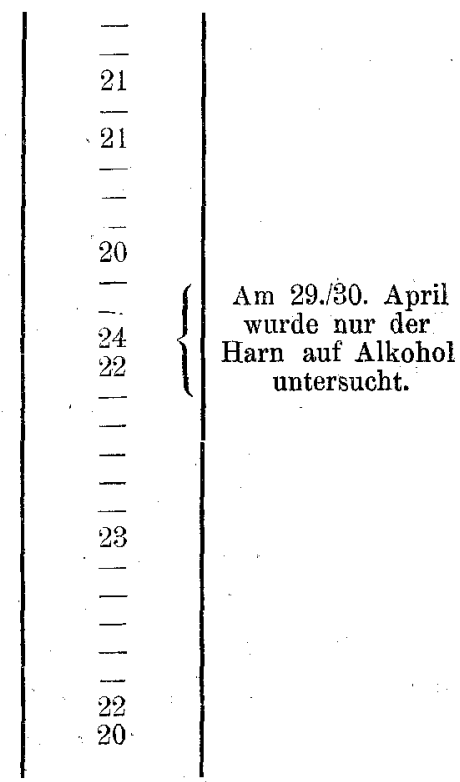

pril bis 1. Mai

1.2. $\mathrm{Mai}$

2.13 .

3.4 . "

4. 15 . " "

5./6. "

$6 . / 7$.

7.18 . "

8.19.

$9 / 10$. "

10/11. "

11./12. "

$12 . / 13$.

13./14.

$\mid$

1) Es gelangten geringe Mengen Harn in den Respirationsapparat. 
Über die vom tierischen Organismus ausgeschiedenen Alkoholmengen. 107

Die ersten drei Versuche an diesem jungen Hunde Nr. 2 sind bereits auf Seite 97 besprochen und die Resultate in Tabelle 3, Seite 100 eingetragen worden. Wir beginnen hier mit Versuch 4 , werden jedoch in der Tabelle 7, welche die Übersicht über sämtliche 11 Versuche bringt, nochmals die Ergebnisse der drei ersten Versuche eintragen.

Vom 4. Versuch ab gelang es stets, den Alkohol des Harnes von dem der Atmung vollständig getrennt zu erhalten.

\section{Versuch am 20./21. April 1910.}

Der Hund wog $5,07 \mathrm{~kg}$ und erhielt in 9,84\% iger Lösung $4,92 \mathrm{ccm}$ resp. pro Körperkilogramm 1,0 cem Alkohol. Das Tier verhielt sich rubig. Versuchsdauer 21 Stunden.

Der Harn enthielt: $0,044 \mathrm{ccm}=0,9 \%$; in der Atmung: $0,062 \mathrm{~cm}$ $=1,3 \%=$ Sa. $0,106 \mathrm{cem}=2,2 \%$. In Prozenten der Gesamtausscheidung: im Harn 41,5\%, in der Atmung $58,5 \%$.

\section{Versuch am 22./23. April 1910.}

Das Tier wog $5,0 \mathrm{~kg}$ und erhielt $4,92 \mathrm{ccm}$ resp. pro Körperkilogramm ca. $1 \mathrm{cem}$ Alkohol. Bald nach der Alkoholzufuhr winselte der Hund kurze Zeit ${ }^{1}$ ). Versuçhsdauer 21 Stunden.

Der Harn enthielt: $0,028 \mathrm{~cm}=0,6 \%$; in der Atmung: 0,057 ccm $=1,1 \%=$ Sa. $0,085 \mathrm{cem}$ Alkohol $=1,7 \%$. In Prozenten der Gesamtausscheidung: im Harn 32,9\%, in der Atmung 67,1\%.

\section{Versuch am 26./27. April 1910.}

Das Tier wog $5,32 \mathrm{~kg}$ und erhielt $4,92 \mathrm{cem}$ resp. pro Körperkilogramm $0,9 \mathrm{ccm}$ Alkohol. Das Tier heulte kurze Zeit nach der Alkoholzufuhr (s. die untenstehende Anmerkung). Versuchsdauer 20 Stunden.

Der Harn enthielt: $0,046 \mathrm{~cm}=0,9 \%$; in der Atmung: $0,026 \mathrm{~cm}$ $=0,5 \%=$ Sa. $0,072 \mathrm{ccm}$ Alkohol $=1,4 \%$. In Prozenten der Gesamtausscheidung: im Harn 63,9\%, in der Atmung 36,1\%.

1) Es ist möglich, dass das Winsein und Heulen, das bei den Versuchen Nr. 2, 5, 6 und 10 beobachtet wurde, nicht auf die Alkoholwirkung zurückzuführen ist, sondern auf das Bestreben des Tieres, aus dem Respirationsapparat herauszukommen; denn bei früheren und späteren Versuchen verhielt sich der Hund ganz ruhig. 
7. Versuch am 29./30. April 1910.

Das Tier wog $5,40 \mathrm{~kg}$ und erbielt $4,92 \mathrm{ccm}$ resp. pro Körperkilogramm 0,9 ccm Alkohol. Der Hund verhielt sich ruhig. Versuchsdauer 24 Stunden. Es wurden ausserhalb des Respirationsapparates nur Alkoholbestimmungen im Harn ausgefübrt.

Der Harn enthielt: $0,032 \mathrm{cem}=0,65 \%$ Alkohol.

\section{Versuch am 30. April bis 1. Mai 1910.}

Der Hund wog $5,4 \mathrm{~kg}$ und erhielt 4,92 ccm resp. pro Körperkilogramm $0,9 \mathrm{cem}$ Alkohol. Das Tier verhielt sich ruhig. Versuchsdauer 22 Stunden.

Der Harn enthielt: $0,019 \mathrm{cem}=0,4 \%$; in der Atmung: $0,015 \mathrm{ccm}$ $=0,3 \%=$ Sa. $0,034 \mathrm{cem}$ Alkohol $=0,7 \%$. In Prozenten der Gesamtausscheidung: im Harn 55,8\%, in der Atmung 44,2\%.

Ein

\section{Versuch, der am 6./7. Mai 1910}

angestellt wurde, konnte deshalb nicht durchgeführt werden, weil der Hund einige Stunden, nachdem er in den Respirationsapparat gebracht worden war, einen Teil des Futters erbrach. Das Tier wog $6,0 \mathrm{~kg}$ und hatte ebenfalls $4,92 \mathrm{ccm}$ resp. pro Körperkilogramm $0,8 \mathrm{ccm}$ Alkohol erhalten.

\section{Versuch am 12.13. Mai 1910.}

Der Hund wog $6,60 \mathrm{~kg}$ und erhielt 4,92 cem, resp. pro Körperkilogramm 0,7 cem Alkohol; er winselte kurze Zeit nach der Alkoholzufuhr ein wenig. Versuchsdauer 22 Stunden.

Der Harn enthielt: $0,022 \mathrm{cem}=0,45 \%$; in der Atmung: $0,020 \mathrm{ccm}$ $=0,41 \% \stackrel{\circ}{=}$ Sa. $0,042 \mathrm{ccm}$ Alkohol $=0,86 \%$. In Prozenten der Gesamtausscheidung: im Harn 52,4\%, in der Atmung 47,6\%.

\section{Versuch am 13./14. Mai 1910.}

Der Hund wog $6,50 \mathrm{~kg}$ und erhielt 4,92 cem resp. pro Körperkilogramm $0,8 \mathrm{~cm}$ Alkohol. Das Tier verhielt sich ruhig. Versuchsdauer 20 Stunden.

Der Harn enthielt: $0,021 \mathrm{ccm}=0,4 \%$; in der Atmung: $0,015 \mathrm{ccm}$ $=0,3 \%=$ Sa. $0,036 \mathrm{ccm}=0,7 \%$. In Prozenten der Gesamtausscheidung: im Harn $58,3 \%$, in der Atmung $41,7 \%$.

Die folgende Tabelle 7 (S. 109) bringt eine Übersicht über die Resultate dieser Reihe. 
Über die vom tierischen Organismus ausgeschiedenen Alkoholmengen. 109

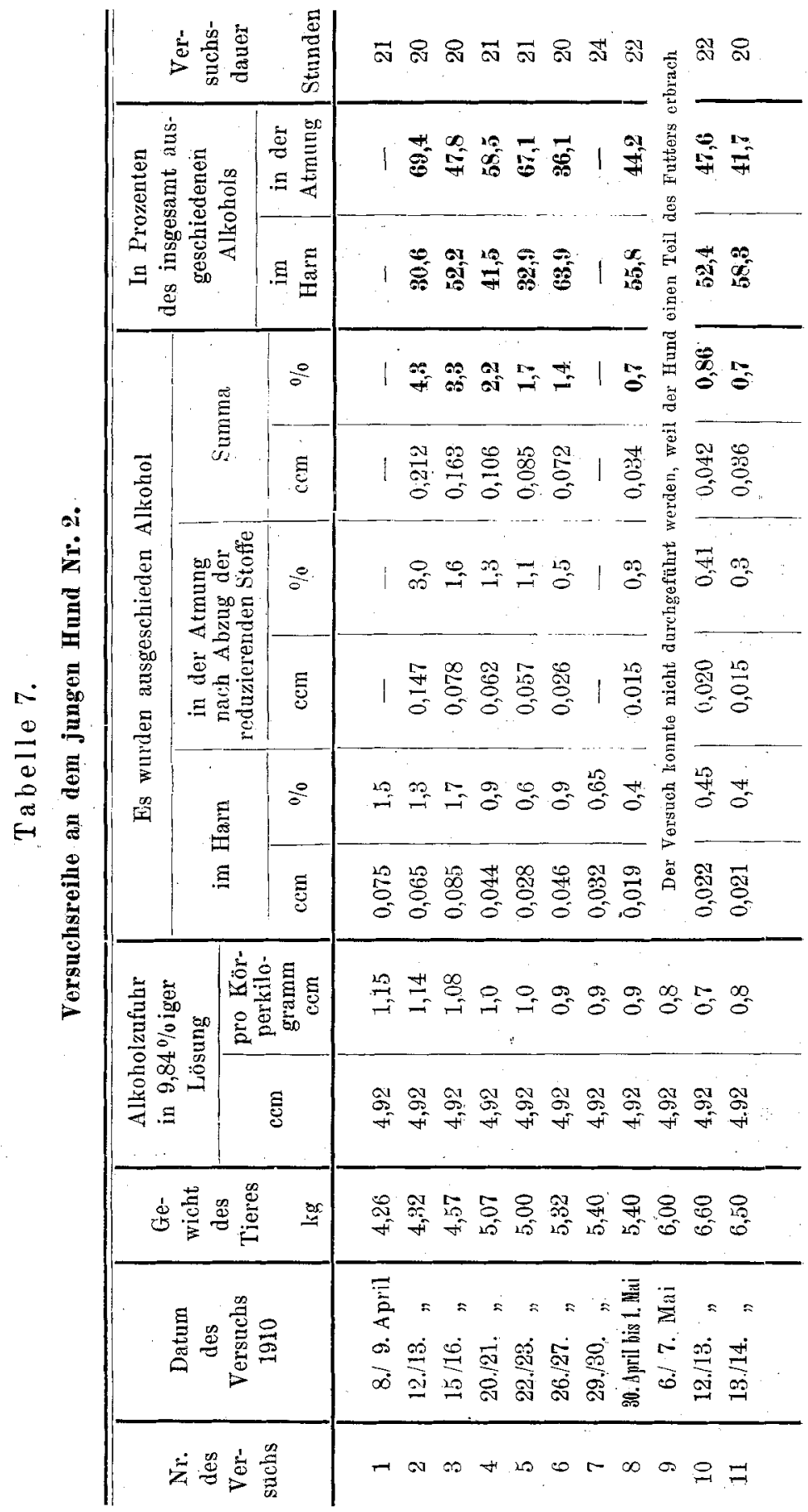


Aus dieser Versuchsreihe ergeben sich hinsichtlich des Einflusses der Gewöhnug auf die Alkoholausscheidung folgende Schlüsse:

Nach der Zufuhr von $0,7-1,15 \mathrm{ccm}$ Alkohol pro Körperkilogramm iu 9,84\% iger Lösung werden vom Hunde zunächst insgesamt rund $4 \%$ des aufgenommenen Alkohols ausgeschieden. Dieser Wert wird unter dem Einfluss der Gewöhnung kontinuierlich geringer bis nach ca. drei Wochen die unterste Grenze mit ca. 1/6 der ursprünglich ausgeschiedenen Menge erreicht ist und durch weitere Gewöhnung nicht mehr unterschritten werden kann. Der von Hunden nach ca. dreiwöchentlicher Gewöhnung an die Aufnahme mässiger Alkoholmengen ausgeschiedene Akóbol beträgt unter $1 \%$ der Zufuhr. Die Verwertung des Alkohols durch den Organismus beträgt unter diesen Bedingungen also über $99 \%$, ist also eine sehr hohe; dabei wurde der Alkohol in einer Dosis gegeben, während z. B. Atwater und Benedict (1. c.) in Versuchen an Menschen ungefähr gleiche Alkoholmengen in sechs Dosen über den Tag verteilt gereicht hatten.

Von der während der vorliegenden Versuchsreihe durch den Organismus des Hundes ausgesehiedenen Alkoholmenge verliessen am ersten Tage rund ${ }^{2 / 3}$ den Körper durch die Atmung, ea. 1/3 durch den Harn, ebenso während des 5. Versuches. Während des 2. Versuches wurden nahezu gleiche Mengen in Harn und Atmung ausgeschieden, während des 4. Versuches eine etwas grössere Quantität durch die Atmung. Bei den späteren Versuchen wurden etwas grössere Alkoholmengen durch die Nieren sezerniert. Wir möchten noch besonders darauf hinweisen, dass sowohl in den Versuchen an dem alten Teckel Nr. 1 als auch an dem während dieser Reihe benutzten jungen Hund Nr. 2 die Gewichtszunahme im Verlauf der Versuche sehr beträchtlich war. Es scheint sich in der Hauptsache um einen starken Fettansatz zu handeln, der ja durch die Versuche Strassmann's ${ }^{1}$ ) und anderer bereits nachgewiesen ist.

C. Einfluss der aufgenommenen Flüssigkeitsmenge auf die Ausscheidung des Alkohols in Harn und Atmung.

Um die Bedeutung dieses Faktors zu erkennen, war es erforderlich, in zwei Versuchsreihen an demselben Tier gleiche

1) Fr. Ștrassmann, Untersuchungen über den Nährwert und die Ausscheidung des Alkohols. Pflüger's Arch. Bd. 49 S. 315. 1891. 
Alkoholmengen zu geben, und zwar einmal in konzentrierterer und zweitens in stärker verdünnter wässeriger Lösung.

Die Resultate der betreffenden beiden Versuchsreihen, welche an dem alten Teckel Nr. 1 durchgeführt wurden, sind unter

A. Versuchsreihe I, Tabelle 2, Seite 96 und

B. Versuchsreihe II, Tabelle 5, Seite 104

mitgeteilt worden.

Während der Versuchsreihe I erhielt der Teckel pro die $\mathbf{2 9 , 4 9} \mathrm{cem}$ Alkohol in 9,84\% \% ger $\mathrm{J}_{\lrcorner}$ösung (pro Körperkilogramm 3,0-3,6 cem Alkohol) kurz nach der Futteraufnahme. Das Volumen der mittels Schlundsonde in den Magen geführten alkoholischen Lösung betrug mit dem zum Ausspülen der Sonde benutzten Wasser ea. $320 \mathrm{cem}$.

Während der zweiten Versuchsreihe wurde pro die die gleiche Alkoholmenge (pro Körperkilogramm 3,1-3,38 cem Alkohol) in $50 \%$ iger Lösung, und zwar $29,74 \mathrm{ccm}$ Alkohol in ca. $60 \mathrm{ccm}$ Flüssigkeit unter das Futter gemischt, welches von dem Hund stets sofort restlos verzehrt wurde. Der Alkobol wurde also während dieser Versuchsreihe II etwa nur in $1 / 5$ des während der ersten Versuchsreihe verabreichten Flüssigkeitsvolums von dem Tier aufgenommen.

Der Vergleich der Tabellen 2 und 5 lässt ganz eklatant erkennen, wie sehr die vom Organismus ausgeschiedene Alkoholmenge in Abhängigkeit steht von dem aufgenommenen Flüssigkeitsvolumen. Nach Zufuhr des Alkohols in starker Verdünnung (29,49 ccm Alkobol in ca. $320 \mathrm{ccm}$ Flüssigkeit) wurde in Versuchsreihe I die enorme Menge von $\mathbf{1 1 , 6 \%}$ der Zufuhr in den Ausscheidungen wiedergefunden, ein Wert, der unter dem Einfluss der Gewöhnung, wie oben bereits konstatiert, bis auf $8,3 \%$, also um rund $30 \%$, zurückgeht. Die infolge der grossen Flüssigkeitszufuhr einsetzende Diurese hat zur Folge, dass die Hauptmenge des Alkohols dureh die Nieren zur Ausscheidung gelangt; nur am ersten Tage wurde wahrscheinlich infolge der sehr starken Alteration des Organismus nach erstmaliger sehr grosser Alkoholzufuhr und hierdurch bedingter forcierter Atmung etwas mehr Alkohol dureh die Atmung ausgeschieden als mit dem Harn. Übrigens gelang es, wie oben mitgeteilt, bei diesem Versuch und bei den drei folgenden nicht, den Alkohol der Atmung von dem des Harnes vollständig zu 
trennen; es besteht also die Möglichkeit, dass auch bereits am ersten Tage etwas mehr Alkohol durch die Nieren sezerniert wurde.

Die Versuchsreihe II, nur unterschieden durch die um ca. ${ }^{4 / 5}$ geringere Flüssigkeitsmenge $(29,74 \mathrm{ccm}$ Alkohol in ca. $60 \mathrm{ccm}$ Flüssiokeit), ergab ganz andere Resultate.

Die starke Diurese, welche wie wir später sehen werden, schon während der ersten Stunden zur Abgabe der Hauptmenge des überhaupt durch die Nieren sezernierten Alkohols führt, fällt hier fort. Der Alkohol bleibt hier also längere Zeit in den Geweben und wird zu einem viel höheren Prozentsatz verwertet. Bereits am ersten Tage gelangen insgesamt nur $4 \%$ zur Ausscheidung, also rund nur etwa die Hälfte der Quantität, welche nach Zufuhr der gleichen Alkoholmenge in ca. $320 \mathrm{ccm}$ Flüssigkeit von dem an Alkohol in dieser Verdünnung gewöhnten Hund ausgeschieden wurde. Unter dem Einfluss der Gewöhnung sinkt dieser Wert auf 2,7\%, also um ein weiteres Drittel herab. Infolge der während der vorliegenden Versuchsreibe II viel geringeren Diurese (der Harn wurde stets erst nach Abschluss der Versuche entleert) gelangen mit einer einzigen Ausnahme (4. Versuch) grössere Quantitäten Alkohol darch die Atmung zur Ausscheidung als durch den Urin (im Mittel 2,1 mal so viel, also die doppelte Menge). -

Es war weiterhin von Interesse, zu untersuchen, welche Alkoholmengen von der in der Atmung überhaupt ausgeschiedenen Quantität innerhalb einzelner Zeitabschnitte an die ausgeatmete Luft abgegeben werden. Wir haben eine grössere Anzahl Versuche durchgeführt, auf die wir nunmehr eingehen. Die Trennung der einzelnen Fraktionen erfolgte dalurch, dass während der Versuche nach bestimmten Zeitabschnitten, die bei den einzelnen Versuchen mitgeteilt werden, die bis dahin zwischen Pumpe und Respirationsapparat angebrachte Glasröhre mit der Bichromatvorlage ausgeschaltet und durch eine mit einer frischen Lösung beschickte Röhre ersetzt wurde. Es gelang so, die gesamte innerhalb der Versuchszeit ausgeatmete Alkoholmenge in $3-4$ Fraktionen zu bestimmen. Übrigens liegen diesbezügliche Untersuchungen vor, die von Bodländer ${ }^{1}$ und Strassmann (l. e.) an Menschen und an Hunden angestellt wurden. Beide Autoren gelangten auf Grund ihrer Versuchsergebnisse zu dem

1) G. Bodländer, Die Ausscheidung aufgenommenen Weingeistes aus dem Körper. Pflüg er's Arch. Bd. 32 S. 398. 1883. 
Schluss, dass die Alkoholanssebeidung in der Atmung wäbrend der ersten Stunde nach der Alkoholzufuhr am stärksten ist, und dass dieselbe allmählieh absinkt.

Unsere Versuche wurden an vier Hunden durchgeführt, und zwar an dem alten Teckel Nr. 1, an dem jungen Hund Nr. 2, an einem zweiten alten Teckel und an einer jungen Hündin desselben Wurfes wie Nr. 2.

An dem alten Teckel Nr. 1 wurden zwei Versuchsreihen durchgeführt. Bei beiden Versuchen erhielt das Tier dieselbe Alkoholmenge, und zwar ca. $3 \mathrm{ccm}$ pro Körperkilogramm. Dagegen wurde während der Versuchsreihe I der Alkohol in stark verdünter Form, nämlich $9,84 \%$ ig, bei der II. Versuchsreihe in konzentrierterer, nämlich in $50 \%$ iger Lösung, verabreicht.

Der junge Hund Nr. 2 erhielt in einer Versuchsreihe III ca. $1 \mathrm{ccm}$ Alkohol pro Körperkilogramm, und zwar in $9,84 \%$ iger Lösung.

Über die Resultate bezüglich der Gesamtausscheidung an Alkohol in Harn und Atmung ist bereits ausführlich berichtet worden; hier sollen zunächst die analytischen Daten für die in einzelnen Fraktionen gewonnenen Alkoholmengen mitgeteilt und im Anschluss daran die Schlussfolgerungen gezogen werden.

I. Versuchsreihe an dem alten Teckel Nr.1.

Die Zufubr betrug ca. $3 \mathrm{ccm}$ pro Kôrperkilogramm in $9,84 \%$ iger Lösung.

Bei den drei ersten Versuchen gelangte Harn in den Apparat, und infolgedessen können die während der einzelnen Zeitabschnitte für den Alkohol der Atmung ermittelten Werte nicht einwandfrei sein. Bei den spăteren Versuchen gelang die Trennung des Alkohols der Atmung von demjenigen des Urins vollständig.

\section{Versuch am 18.19. April 1910.}

Die Bichromatvorlagen wurden, und zwar 1 . nach $8^{1 / 4}$ Stunden, 2. nach weiteren $3^{1 / 4}$ Stunden und 3. nach weiteren $9^{1 / 2}$ Stunden ausgewechselt und auf Alkohol untersucht. Die Daten für die einzelnen Zeitabschnitte, in denen die verschiedenen Fraktionen während des 1. Versuches gewonnen wurden; 'enthält die folgende Tabelle, wie auch diejenigen für die Versưche 2 and 3. Die Pflüger's Archiv für Physiologie. Bd. 138. 
bei alkoholfreiem Regime in der Atmung gefundenen reduzierenden Stoffe, und zwar eine $0,00266 \mathrm{ccm}$ Alkohol pro Stunde entsprechende Menge haben wir bereits in Abzug gebracht. Das Resultat war folgendes:

Tabelle 8.

\begin{tabular}{c|c|c|c|}
\hline $\begin{array}{c}\text { Für die } \\
\text { Fraktion }\end{array}$ & Stunden & $\begin{array}{c}\text { Direkt ermittelte Werte } \\
\text { für den Alkoholgehalt } \\
\text { der Atmung } \\
\text { ccm }\end{array}$ & $\begin{array}{c}\text { Pro Stunde nach } \mathrm{Ab}- \\
\text { zug der reduzierenden } \\
\text { Stoffe } \\
\text { Alkohol ccm }\end{array}$ \\
\hline
\end{tabular}

1. Versuch am 18.19. April 1910.

\begin{tabular}{l|c|c|c}
1 & $0-81^{1 / 4}$ & 0,900 & 0,106 \\
2 & $81^{1 / 4-11^{1 / 2}}$ & 0,331 & 0,099 \\
3 & $11^{1 / 2-21}$ & 0,687 & 0,069
\end{tabular}

2. Versuch am 21.22. April 1910.

\begin{tabular}{l|c|l|l}
1 & $0-6^{1 / 2}$ & 0,716 & 0,105 \\
2 & $6^{1 / 2-14}$ & 0,756 & 0,098 \\
3 & $14-71$ & 0,398 & 0,054
\end{tabular}

\section{Versuch am 28.24. April 1910.}

\begin{tabular}{l|r|l|l}
1 & $0-4$ & 0,366 & 0,089 \\
2 & $4-8$ & 0,328 & 0,079 \\
3 & $8-12$ & 0,305 & 0,073 \\
4 & $12-19$ & 0,310 & 0,041 \\
5 & $19-22$ & 0,073 & 0,021
\end{tabular}

Im Hinblick auf die Tatsache, dass uns die Trennung des Alkohols der Atmung vom Alkohol des Urins nicht vollständig gelang, ziehen wir aus den eben mitgeteilten analytischen Daten keine Schlüsse.

Tabelle 9.

\begin{tabular}{l|l|c|c|c|c}
\hline \multirow{4}{*}{ Fraktion } & Stunden & $\begin{array}{c}\text { Direkt } \\
\text { ermittelte } \\
\text { Werte } \\
\text { Summa } \\
\text { cem Alkohol }\end{array}$ & $\begin{array}{c}\text { Nach Subtrak- } \\
\text { tion der redu- } \\
\text { zierenden Stoffe } \\
\text { pro Stunde } \\
\text { ccm Alkohol }\end{array}$ & $\begin{array}{c}\text { In Prozenten der in } \\
\text { d. Atmung insgesamt } \\
\text { ausgeschiedenen } \\
\text { Alkoholmenge } \\
\text { pro Stunde }\end{array}$ \\
\hline
\end{tabular}

4. Versuch am 25./26. April 1910.

\begin{tabular}{l|l|l|l|l}
1 & $0-4$ & 0,245 & 0,058 & 6,4 \\
2 & $4-8$ & 0,305 & 0,073 & 8,0 \\
3 & $8-21$ & 0,367 & 0,025 & 2,7
\end{tabular}

Durch Evacuieren des Apparates

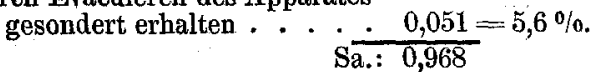

Nach Abzug der reduz. Stoffe Sa.: 0,912 
Über die vom tierischen Organismus ausgeschiedenen Alkokolmengen. 115

\begin{tabular}{l|c|c|c|c}
\hline \multirow{3}{*}{ Fraktion } & Stunden & $\begin{array}{c}\text { Direkt } \\
\text { ermittelte } \\
\text { Werte } \\
\text { Summa } \\
\text { ccm Alkohol }\end{array}$ & $\begin{array}{c}\text { Nach Sub- } \\
\text { traktion der } \\
\text { reduzierenden } \\
\text { Stoffe } \\
\text { ccm Alkohol }\end{array}$ & $\begin{array}{c}\text { In Prozenten der in } \\
\text { der Atmung ins- } \\
\text { gesamt aus- } \\
\text { geschiedenen Alko- } \\
\text { holmenge proStunde }\end{array}$ \\
\hline
\end{tabular}

5. Versuch am 27./28. April 1910.

\begin{tabular}{l|c|c|c|c}
1 & $0-3$ & 0,142 & 0,044 & 4,3 \\
2 & $3-7^{3 / 4}$ & 0,392 & 0,080 & 7,8 \\
3 & $7^{3 / 4}-21^{1 / 2}$ & 0,555 & 0,037 & $\left.3,6^{1}\right)$
\end{tabular}

Nach Abzug der reduzierenden

Sa. $\overline{1,089}$

Stoffe ....... Sa. 1,032

II. Versuchsreihe an demselben alten Teckel Nr. 1.

Das Tier erhält die gleiche Alkoholmenge (ca. $3 \mathrm{ccm}$ pro Körperkilogramm), jedoch in konzentrierter Form (ca. $50 \% \mathrm{ig}$ ).

\begin{tabular}{l|l|c|c|c}
\hline \multirow{3}{*}{ Fraktion } & Stunden & $\begin{array}{c}\text { Direkt } \\
\text { ermittelte } \\
\text { Werte } \\
\text { Summa } \\
\text { ccm Alkohol }\end{array}$ & $\begin{array}{c}\text { Nach Sub- } \\
\text { traktion der } \\
\text { reduzierenden } \\
\text { Stoffe } \\
\text { ccm Alkohol }\end{array}$ & $\begin{array}{c}\text { In Prozenten der in } \\
\text { der Atmung ins- } \\
\text { gesamt aus- } \\
\text { geschiedenen Alko- } \\
\text { holmenge pro Stunde }\end{array}$ \\
\hline
\end{tabular}

1. Versuch am 2./3. Mai 1910.

\begin{tabular}{l|c|l|l|l}
1 & $0-3$ & 0,142 & 0,044 & 4,3 \\
2 & $3-10^{1 / 4}$ & 0,562 & 0,075 & 7,3 \\
3 & $10^{1 / 4}-20^{1 / 2}$ & 0,348 & 0,031 & 3,0 \\
4 & $20^{1 / 2}-22^{1 / 2}$ & 0,014 & 0,004 & 0,4
\end{tabular}

Im Apparat zurückgebliebeu . . $0,024=2,3 \%$

Nach Abzug der reduzierenden

Sa. $\frac{0,024}{1,090}$

Stoffe . . . . . Sa. 1,081,

2. Versuch am 4./5. Mai 1910.

\begin{tabular}{l|c|c|c|c}
1 & $0-3$ & 0,131 & 6,041 & 4,9 \\
5 & $3-10^{1 / 4}$ & 0,472 & 0,062 & 7,4 \\
$10^{1 / 4}-23^{3 / 4}$ & 0,285 & 0,018 & 2,2
\end{tabular}

Im Apparat zurückgeblieben . $\cdot \underline{0,014}=1,7 \%$

Nach Abzug der reduzierenden

Sa. $\overline{0,902}$

Stoffe........ Sa. 0,839

3. Versuch am 10./11. Mai 1910.

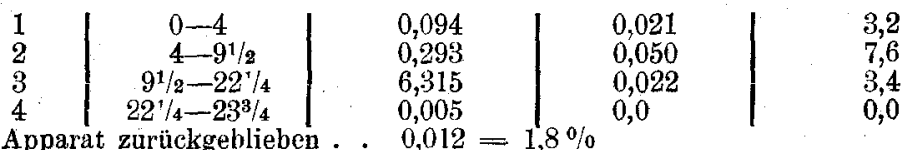

Im Apparat zurückgeblieben . . $0,012=1,8 \%$

Nach Abzug der reduzierenden

Sa. $\overline{0,719}$

Stoffe . . . . . Sa. 0,656

1) In der dritten Fraktion wurden die geringen im Apparat verbliebenen Alkoholmengen mitbestimmt. 


\begin{tabular}{|c|c|c|c|c|}
\hline Fraktion & Stunden & $\begin{array}{l}\text { Direkt } \\
\text { ermittelte } \\
\text { Werte } \\
\text { Summa } \\
\text { ccm Alkohol }\end{array}$ & $\begin{array}{l}\text { Nach Subtrak- } \\
\text { tion der redu- } \\
\text { zierenden Stoffe } \\
\text { pro Stunde } \\
\text { ccm Alkohol }\end{array}$ & $\begin{array}{c}\text { In Prozenten der in } \\
\text { der Atmung ins- } \\
\text { gesamt ausgeschie- } \\
\text { denen Alkoholmenge } \\
\text { pro Stunde }\end{array}$ \\
\hline
\end{tabular}

4, Versuch am 18.19. Mai 1910.

\begin{tabular}{|c|c|c|c|c|}
\hline 7 & $\begin{array}{r}0-4 \\
4-10 \\
10-28\end{array}$ & $\begin{array}{l}0,095 \\
0,198 \\
0,184\end{array}$ & $\begin{array}{l}0,021 \\
0,030 \\
0,011\end{array}$ & $\begin{array}{ll}5,0 \\
\quad & 7,2 \\
\quad & 2,6^{11}\end{array}$ \\
\hline
\end{tabular}

Nach Abzug der reduzierenden

Stoffe .. . . . Sa. 0,416

5. Versuch am 20./21. Mai 1910 .

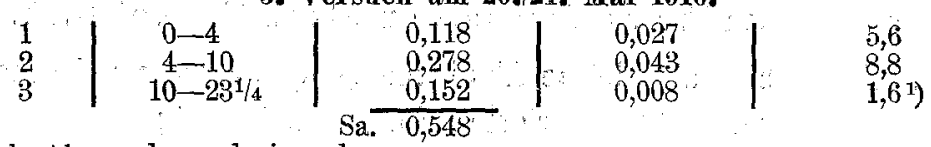

Nach Abzug der reduzierenden

Stoffe . . . . Sa. 0,486

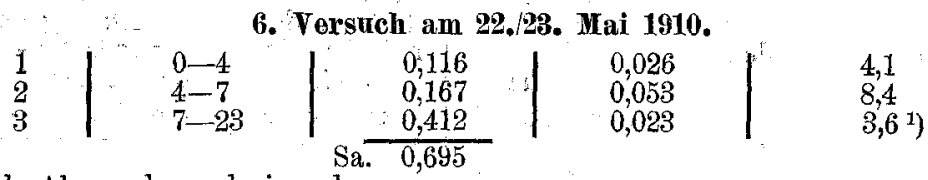

Nach Abzug der reduzierenden

Stoffe ........ Sa. 0,634

\begin{tabular}{|c|c|c|c|c|}
\hline $\begin{array}{l}1 \\
2 \\
3\end{array}$ & $\begin{array}{c}0-4 \\
4-10 \\
10-24\end{array}$ & $\begin{array}{l}0,127 \\
0,306 \\
0,264\end{array}$ & $\begin{array}{l}0,029 \\
0,048 \\
0,016\end{array}$ & $\begin{array}{l}4,6 \\
7,6 \\
\left.2,5^{1}\right)\end{array}$ \\
\hline
\end{tabular}

7. Versuch am 24./25. Mai 1910.

Nach Abzug der reduzierenden

Stoffe . . . . . Sa. 0,633

Überblicken wir die Resultate der einzelnen Versuche beider Reihen, so gelangen wir zu dem Schluss, dass trotz der Zufuhr sehr verschieden grosser Wassermengen mit der gleichen Alkoholquantität (in Reihe I ca. $320 \mathrm{ccm}$, in Reihe II ca. $60 \mathrm{ccm}$ ) bezüglich der pro Stunde während der verschiedenen Zeitabschnitte durch die Atmung ausgeschiedenen Alkoholmengen wesentliche Unterschiede nicht bestehen. Es können daher bei der Zusammeustellung der Daten zwecks Bestimmung der Mittelwerte in der nächsten Tabelle 10 sämtliche in Betracht kommenden Versuchsergebnisse beider Reihen benutzt werden.

1) In der dritten Fraktion wurden die geringen im Apparat zurückgebliebenen Alkoholmengen mitbestimmt. 
Über die vom tierischen Organismus:ausgeschiedenen Alkoholmengen. 117

Tabelle 10.

Übersicht über die nach der Zufuhr von ca. $3 \mathrm{ccm}$ Alkohol pro Körperkilogramm während einzelner Zeitabschnitte durch die Atmung pro Stunde ausgeschiedenen Alkoholmengen in Prozenten des durch die Atmung insgesamt ausgeschiedenen Alkohols.

\begin{tabular}{|c|c|c|c|c|c|c|c|c|c|}
\hline \multirow[b]{2}{*}{ Reihe } & \multirow[b]{2}{*}{ 高 } & \multicolumn{2}{|c|}{ 1. Abschnitt } & \multicolumn{2}{|c|}{ 2. Abschnitt } & \multicolumn{2}{|c|}{ 3. Abschnitt } & \multicolumn{2}{|c|}{ 4. Abschnitt } \\
\hline & & $\begin{array}{l}\text { Dauer } \\
\text { Stund. }\end{array}$ & $\begin{array}{c}\text { Alkohol } \\
\text { pro } \\
\text { Stunde } \\
\%\end{array}$ & $\begin{array}{l}\text { Dauer } \\
\text { Stund. }\end{array}$ & $\begin{array}{c}\text { Alkohol } \\
\text { pro } \\
\text { Stunde } \\
0 \%\end{array}$ & $\begin{array}{l}\text { Dauer } \\
\text { Stund. }\end{array}$ & $\begin{array}{c}\text { Alkohol } \\
\text { pro } \\
\text { Stunde } \\
\% \\
\text { \% }\end{array}$ & $\begin{array}{l}\text { Dauer } \\
\text { Stund }\end{array}$ & $\begin{array}{c}\text { Alkoho } \\
\text { pro } \\
\text { Stunde } \\
0 \%\end{array}$ \\
\hline $\begin{array}{c}\mathrm{I} \\
(9,84 \% \text { ige } \\
\text { alkoholische } \\
\text { Lösung) }\end{array}$ & 4 & $\frac{4}{3}$ & $\begin{array}{r}6,4 \\
\hdashline \quad, 3\end{array}$ & $\begin{array}{l}4 \\
4^{3 / 4}\end{array}$ & $\begin{array}{l}8,0 \\
7,8\end{array}$ & $\begin{array}{l}13 \\
13^{3 / 4}\end{array}$ & $\begin{array}{l}2,7 \\
3,6\end{array}$ & 二 & 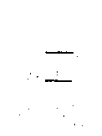 \\
\hline $\begin{array}{c}\text { II } \\
(50 \% \text { ige al- } \\
\text { koholische } \\
\text { Lösung) }\end{array}$ & $\begin{array}{l}1 \\
2 \\
3 \\
4 \\
5 \\
5 \\
6 \\
7\end{array}$ & $\begin{array}{l}9 \\
3 \\
4 \\
4 \\
4 \\
4 \\
4\end{array}$ & $\begin{array}{l}4,3 \\
4,9 \\
3,2 \\
5,0 \\
5,6 \\
4,1 \\
4,6\end{array}$ & $\begin{array}{l}7^{1 / 4} \\
7^{1 / 4} \\
5^{1 / 2} \\
6 \\
6 \\
3 \\
6 \\
6\end{array}$ & $\begin{array}{l}7,3 \\
7,3 \\
7,6 \\
7,2 \\
8,8 \\
8,4 \\
7,6\end{array}$ & $\begin{array}{l}10^{1 / 4} / 4 \\
13^{1 / 2} \\
12^{3 / 4} \\
13 \\
13^{1 / 4} \\
16 \\
14\end{array}$ & $\begin{array}{l}3,0 \\
2,2 \\
3,4 \\
2,6 \\
1,6 \\
3,6 \\
2,5\end{array}$ & $\begin{array}{l}\frac{2}{11 / 2} \\
\frac{1}{-} \\
- \\
-\end{array}$ & $\begin{array}{l}0,4 \\
0,0 \\
- \\
- \\
-\end{array}$ \\
\hline Mittelwe & & $3^{3 / 4}$ & 4,7 & $5^{1 / 2}$ & 7,8 & 13 & 2,8 & - & - \\
\hline
\end{tabular}

Es ist auffallend, dass während des zweiten im Mittel $5^{1 / 2-}$ stündigen Zeitabschnittes; also $3^{3 / 4}-9^{1 / 4}$ Stunden nach der Zufuhr, viel grössere. Alkoholmengen (im Mittel 7,8\% pro Stunde) durch die Atmung ausgeschieden werden, als während der ersten 3 bis 4 Stunden $(4,7 \%)$. Geringe Alkoholmengen bleiben allerdings nach Abschluss der Versuche im Respirationsapparat zurück; wir haben diese Quantitäten in einigen Versuchen (Reihe I Versuch 4, Reihe II Versuch 1,2 und 3) gesondert bestimmt; wenn wir diese kleinen Alkoholmengen aber auch der ersten Fraktion zurechnen, wozu wir nicht berechtigt wären, würden sich doch bei weitem nicht so hohe Werte für den pro. Stunde während des ersten Zeitabschnittes durch die Atmung ausgeschiedenen Alkohol ergeben, wie wir sie für den zweiten Zeitabschnitt von durchschnittlich sechsstündiger Dauer pro Stunde gefunden haben. Allerdings konnte doch noch folgendes in Frage kommen: Nach 22-24 Stunden waren, wie durch besondere Versuche nachgewiesen wurde, die in dem Respirationsapparat zurückgebliebenen Alkoholmengen minimal, weil eben mehrere Stunden, nachdem kein Alkohol mehr, oder doch nur minimale Mengen ausgeatmet waren, der Apparat fortwährend mit Luft durchspült worden war, welche die zu Beginn noch vorhandenen Alkoholmengen längst in die Bichromatyorlagen hinübergerissen batte; dagegen war es in 
Anbetracht der Grösse des Apparates wohl möglich, dass die nach dem ersten Zeitabschnitt, also nach $3^{3 / 4}$ Stunden vom Tier bereits ausgeschiedenen Alkoholmengen noch nicht vollständig in die Vorlagen übergegangen, sondern zum Teil in dem anfangs auch noch kälteren Apparat zurückgeblieben sein konnten. Verhielte sich die Sache so, dann wäre die während des zweiten $5^{1 / 2}$ stündigen Zeitabschnittes gefundene vermehrte Alkoholabgabe durch die Atmung eine nur scheinbare gewesen, bedingt durch die zu Beginn der zweiten Fraktion im Respirationsapparat noch vorhandenen Alkoholmengen, die zu der ersten Fraktion gehörten. Die für die einzelnen Versuchstage in der Atmung insgesamt gefundenen Alkoholmengen könnten natürlich infolge der vorstehenden Erwägungen in keiner Weise verändert werden; die betreffenden analytischen Daten sind einwandfrei. Um aber zu prüfen, ob in der Tat der höhere Wert für den Alkoholgehalt der zweiten Fraktion auf eine in dem Apparat verbliebene Alkoholmenge der ersten Fraktion zurïckzuführen ist, stellten wir besondere Versuche an, in denen die bei der ersten Versuchsanstellung mögliche Fehlerquelle vermieden wurde. Zu dem Zweck wurde den Hunden nach der Verabreichung von Alkohol ein Glaszylinder mit Gummihaube über den Kopf gestreift; die Gummihaube umsehloss einerseits fest den Zylinder und legte sich auf der anderen Seite genügend dicht an den Hals des Tieres an. Einige kleine Öffnungen der Gummihaube, durch die Glasröhren gesteckt wurden, ermöglichten allein den Eintritt der Luft in den Zylinder. An der vorderen Seite des Zylinders, unmittelbar vor der Nase des Hundes, war ein Glasrohr luftdicht eingesetzt worden, durch das die ausgeatmete Luft mittels Saugpumpen durch die Bichromatschwefelsäurevorlagen gesaugt wurde. Eine an Stelle des Glaszylinders eigens konstruierte Blechhaube bewährte sich ebenfalls für den Zweck. Auf diese Weise war es uns möglich, die von den in Ruhelage fixierten Hunden ausgeatmeten Alkoholmengen nach beliebigen Zeitabschnitten leisht getrennt zu bestimmen, nnd zwar einfach durch Auswechselung der Vorlagen. Eine Hautatmung kommt beim Hunde so gut wie gar nicht in Frage und konnte dieselbe daher unberücksichtigt bleiben. Da den Tieren die Atmung durch den ziemlich engen Zylinder bzw. durch die Blechhaube auf die Dauer erschwert wurde, haben wir die einzelnen Versuche im allgemeinen nur 5-10 Stunden ausgedehnt; in zwei Fällen wurden die Versuche 231/2 Stunden durchgefuhrt. Die Fraktionen wurden bis zu Beginn der sechsten Stunde 
Öber die vom tierischen Organismus ausgeschiedenen Alkoholmengen. 119

nach je 1 bzw. 2 Stunden, später nach längerer Zeit, entnommen und gesondert auf Alkohol untersucht. Es wurden insgesamt sechs Versuche, und zwar vier an einem alten männlichen Teckel und zwei an einer jungen Hündin, durchgeführt. Die Tiere erhielten pro Körperkilogramm ca. 3,3-4,5 ccm Alkohol in ca. 50\% iger Lösung; es handelte sich also um toxische Dosen. Die Atemfrequenz war zum Teil ausserordentlich erhöht und unregelmässig. Übrigens sind die für die einzelnen Stunden eingetragenen Werte für die Atemfrequenz keine genauen Mittelwerte für die betreffenden Zeitabschnitte, sondern in der Weise gefunden, dass während der betreffenden Stunde einbis viermal die Zahl der Atemzüge pro Minute gezählt wurde.

Die Versuchsergebnisse an den beiden Hunden waren folgende:

Alkoholzufuhr: I. Der männliche Hund erhält insgesamt $35,79 \mathrm{ccm}$ (ca. $50 \%$ ), resp. pro Körperkilogramm $3,25 \mathrm{ccm}$; II. die Hündin erhält insgesamt $23,20 \mathrm{ccm}$ (ca. $50 \%$ ), resp. pro Körperkilogramm 4,46 ccm.

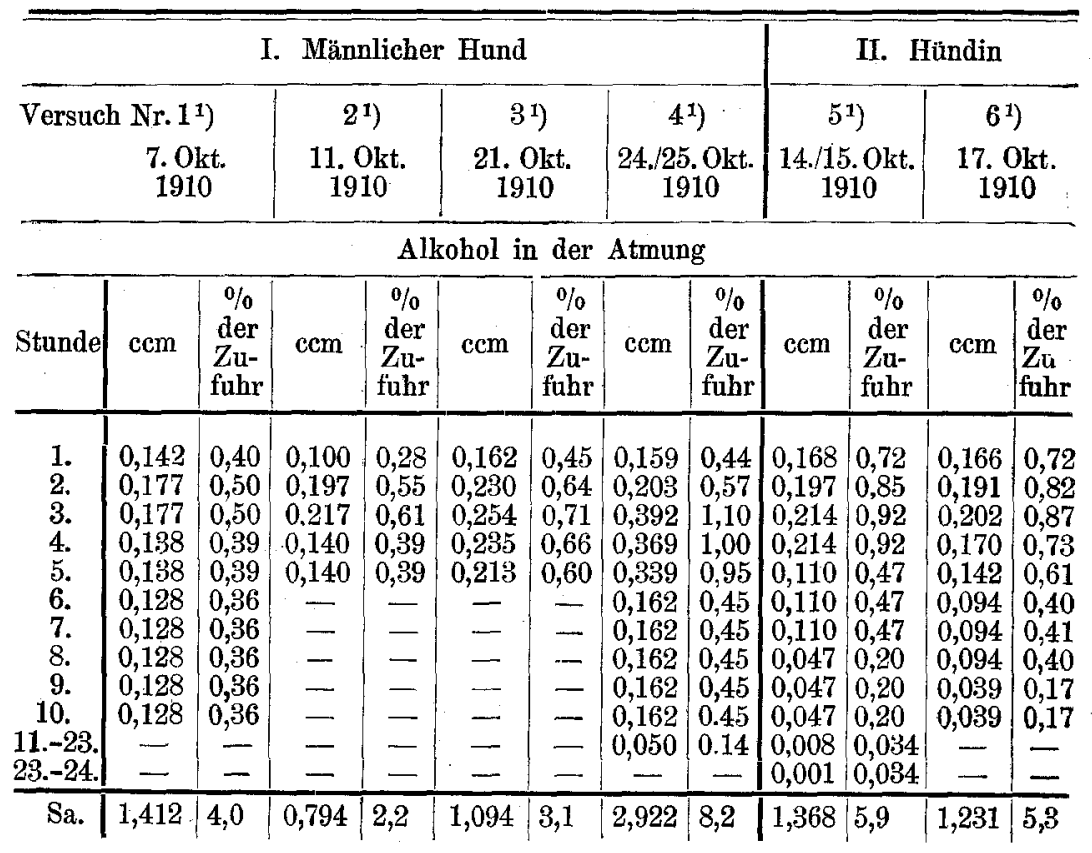

1) Die Atemfrequenz betrug bei den einzelnen Versuchen:

\begin{tabular}{|c|c|c|c|c|c|c|c|}
\hline \multirow{2}{*}{\multicolumn{2}{|c|}{ in der 1. Stunde }} & Nr. 1 & Nr. 2 & Nr. 3 & Nr. 4 & Nr. 5 & Nr. 6 \\
\hline & & 150 & 28 & 42 & 45 & 104 & 100 \\
\hline 3 & $\# 2$. & 120 & 120 & 29 & 144 & 120 & 100 \\
\hline ע & 3. & 120 & 160 & 27 & 170 & 116 & 120 \\
\hline$y$ & 4. & 100 & 120 & 38 & 186 & 70 & 100 \\
\hline » & 5. & - & $\ldots$ & 120 & 190 & 60 & - \\
\hline
\end{tabular}


Bei dem vierten Versuch wurden aussergewöhnlich hohe Werte für den Alkoholgebalt der Atmung gefunden. Das Tier war während dieses Versuches besonders stark alteriert, sehr unruhig und atmete sehr foreiert:

Setzen wir nun die während der ersten Stunde bei den einzelnen Versuchen ausgeschiedenen Alkoholmengen gleich 100, so ergebén sich für die späteren Stunden folgende Werte:

\begin{tabular}{|c|c|c|c|c|c|c|c|}
\hline \multirow{2}{*}{ Stunde } & \multicolumn{6}{|c|}{ Versuch } & \multirow{2}{*}{$\begin{array}{c}\text { Also } \\
\text { im Mittel } \\
\text { der sechs } \\
\text { Versuche }\end{array}$} \\
\hline & 1 & 2 & 8 & 4 & $\cdots 5$ & 6 & \\
\hline $\begin{array}{l}1 . \\
2 . \\
3 . \\
4 . \\
5 . \\
6 .\end{array}$ & $\begin{array}{l}100 \\
125 \\
125 \\
97 \\
97 \\
90\end{array}$ & $\begin{array}{l}100 \\
197 \\
217 \\
140 \\
140 \\
\end{array}$ & $\begin{array}{l}100 \\
142 \\
157 \\
145 \\
131 \\
\end{array}$ & $\begin{array}{l}100 \\
128 \\
247 \\
233 \\
213 \\
102\end{array}$ & $\begin{array}{r}100 \\
117 \\
127 \\
127 \\
65 \\
65\end{array}$ & $\begin{array}{r}100 \\
115 \\
122 \\
108 \\
86 \\
57\end{array}$ & $\begin{array}{l}100 \\
137 \\
166 \\
141 \\
122 \\
78\end{array}$ \\
\hline
\end{tabular}

Aus den obigen Daten ergibt sich folgendes:

Die maximalen Alkoholmengen werden also unter den gewähiten Bedingungen während der dritten Stunde ausgeatmet; im Vergleich zứ ersten Stunde war der betr. Wert um rund zwei Drittel höher. Die in der zweiten und vierten Stunde ausgeatmete Alkoholquantitat st annähernd gleich und um ein Drittel höher als in der ersten Stunde. In der fünften Stunde ergibt der Mittelwert noch eine um ein Füuftel höhere Alkoholmenge gegenübër der ersten Stunde. Von der sechsten Stunde ab wird der Alkoholgehalt der ausgeatmeten Luft im Vergleich zur ersten Stunde erheblich geringer und sinkt dann weiter $a b$.

Die Tatsache, dass verhältnismässig spät, nämlich erst während der dritten Stunde, die maximalen Alkoholmengen ausgeatmet werden, kann wobl darauf zurückgeführt werden, dass kurz nach der Einführung des Alkohols in den Magen die Resorption noch nieht vollständig erfolgt ist; ausserdem dürfte der Alkobol zunächist zu einem höheren Prozentsatz durch die Lipoide des Organismus festgelegt werden, als später.

Wir beabsichtigen, weitere Versuche anzustellen, um u. auch die Frage zu entscheiden, ob die durch die Atmung innerhalb bestimmter Zeitabschnitte ausgeschiedenen Alkoholmengen beim hungernden Tier dasselbe Verhältnis zu einander aufweisen, wie wir es bei normal emährten Tieren gefunden haben, und ob insbesondere auch die ausgesehiedenen Alkoholmengen die gleichen sind. 
Versuchsreihe an dem jungen Hund Nr. 2.

Wir versuchten an zwei Tagen den Alkohol der Atmung in je zwei Fraktionen zu bestimmen. In Anbetracht der geringen Alkoholzufuhr bei dem jungen Hund und der Tatsache, dass nur ca. $1 \%$ der aufgenommenen Alkoholmenge in der Atmung zu erwarten-war, stossen solche Versuche natürlich auf grosse Schwierigkeiten. Immerhin haben wir bei beiden Versuchen befriedigende Übereinstimmung erzielt.

Das Tier erhielt an den beiden Versuchstagen die gleichen Alkoholmengen nach der Fütterung, und zwar ca. 1 cem pro Körperkilogramm in $9,84 \%$ iger Lösung.

Tabelle 13.

\begin{tabular}{|c|c|c|c|c|}
\hline Fraktion & Stunden & $\begin{array}{l}\text { In der Atmung } \\
\text { direkt } \\
\text { ermittelter Wert } \\
\text { ccm }\end{array}$ & $\begin{array}{l}\text { Pro Stunde durch } \\
\text { die Atmung ausge- } \\
\text { schiedene Alkobol- } \\
\text { mengen nach Sub- } \\
\text { traktion der redu- } \\
\text { zierenden Stoffe } \\
\text { ccm }\end{array}$ & $\begin{array}{l}\text { In Prozenten } \\
\text { der in der Atmung } \\
\text { insgesamt } \\
\text { ausgeschiedenen } \\
\text { Alkoholmengen } \\
\text { pro Stunde }\end{array}$ \\
\hline
\end{tabular}

1. Versuch am 20./21. April 1910.

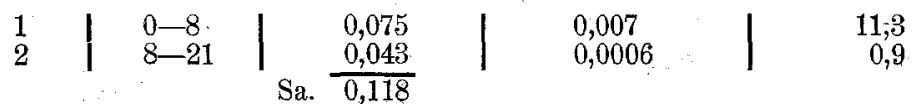

Nach Abzug der reduzie-

renden Stoffe . $\because$ Sa. 0,062

$$
\begin{array}{l|ll|c|c|c}
1 & \multicolumn{5}{c}{\text { 2. Versuch am 22./23. April 1910. }} \\
2 & 0-8 & 8-21 & \left.\right|_{\text {Sa. }} \frac{0,068}{0,113} & 0,0058 & 10,2 \\
0,00077 & 1,35
\end{array}
$$

Nach Abzug der reduzie-

renden Stoffe . . . Sa. 0,057

Wir ersehen aus diesen Versuchen, dass innerhalb der ersten acht Stunden nach der Alkoholzufuhr von ca. 1 cem pro Körperkilogramm in $9,84 \%$ iger Lösung bereits rund $80-90 \%$ der überhaupt durch die Atmung ausgeschiedenen Menge ausgeatmet werden. -

Gewinnung des durch die Nieren sezernierten Alkohols in zwei Fraktionen.

Um zu erfahren, welche Alkoholmengen ca. $11 / 2-2$ Stunden nach der Zufuhr durch die Nieren sezerniert werden; haben wir in drei Versuchen an dem alten Teckel Nr. 1 nach Alkoholgaben von ca. 3 ccm pro Körperkilogramm in 9,84\% \% iger Lösung den Tagesharn in je zwei Fraktionen gewonnen, und es sind diese Fraktionen gesondert auf Alkohol untersucht worden. 


\section{Versuch am 25./26. April 1910.}

Das $8,97 \mathrm{~kg}$ schwere Tier erhielt 29,49 cem Alkohol in 9,84\% \% iger Lösung. Die erste bereits $1^{1 / 2}$ Stunden nach der Alkoholzufuhr entleerte Harnmenge enthielt $1,00 \mathrm{cem}$ Alkohol $=3,4 \%$ der Zufubr. Die zweite Harnfraktion wurde innerhalb der übrigen 191/2 Stunden dieses Versuchstages gesammelt und enthielt $0,720 \mathrm{ecm}$ Alkohol $=2,43 \%$ der Zufuhr.

Es wurden also bereits $11 / 2$ Stunden nach der Alkoholzufuhr $58,2 \%$ der gesamten im Harn ausgeschiedenen Alkoholmenge durch die Nieren sezerniert; also insgesamt gelangten ausser diesem $1,00 \mathrm{ccm}$ Alkohol nur noch $0,720 \mathrm{ccm}=41,8 \%$ zur Ausscheidung.

\section{Versuch am 28./29. April 1910.}

Der Harn wurde in zwei Fraktionen und zwar 2 Stunden und 23. Stunden nach der Alkoholzufuhr gewonnen und analysiert.

\begin{tabular}{c|c|c|c}
\hline Fraktion & Stunden & $\begin{array}{c}\text { Alkohol im Harn } \\
\text { cem }\end{array}$ & Prozent der Zufuhr \\
\hline 1 & $0-2$ & 1,38 & 4,68 \\
2 & $2-23$ & 0,191 & 0,65
\end{tabular}

In Prozenten der Gesamtausscheidung: in der 1. Fraktion 87,9\%, in der 2. Fraktion $12,1 \%$.

\section{Versuch am 27.28. Mai 1910.}

Der Urin wurde in zwei Fraktionen, und zwar nach 2 Stunden und nach $21 \frac{1}{2}$ Stunden gewonnen und analysiert.

\begin{tabular}{c|c|c|c}
\hline Fraktion & Stunden & $\begin{array}{c}\text { Alkohol im Harn } \\
\text { ccm }\end{array}$ & Prozent der Zufuhr \\
\hline 1 & $\begin{array}{l}0-2 \\
2-21^{1 / 2}\end{array}$ & 1,34 & 4,54 \\
\hline
\end{tabular}

In Prozenten der Gesamtausscheidung: in der 1. Fraktion 77,4\%, n der 2. Fraktion $22,6 \%$.

Aus diesen drei Versuchen ergibt sich das Resultat, das bereits innerhalb der ersten $1^{1 / 2}-2$ Stunden nach der Aufnahme von ca. $3 \mathrm{ccm}$ Alkohol pro Körperkilogramm die Hauptmenge des überhaupt durch die Nieren sezernierten Alkohols im Urin zur Ausscheidung gelangt. - 
Alkoholausscheidung. im Harn des Menschen.

Wir haben schliesslich an den Herren Dr. med. H. Gerhartz, Dr. med. R. Förster und dem einen von uns (Baudrexel) in je einem Versuch nach der Aufnahme von 0,8-1 cem Alkohol pro Körperkilogramm in einer Dosis die im Harn insgesamt zur Ausscheidung gelangende Alkoholmenge bestimmt.

Es ergaben sich folgende Resultate:

1. Versuch an Dr. med. H. Gerhartz am 20./21. April 1910.

Dr. Gerhartz ist 30 Jahre alt, gesund, mit gut ausgebildeter Muskulatur, $80 \mathrm{~kg}$ schwer, an mässigen Alkoholgenuss gewöhnt.

Am Montag, den 18. April, hatte Gerhartz ein Glas Bier getrunken, am Dienstag, den 19. April, keinen Alkohol genossen, auch nicht am 20. April bis zum Beginn der Versuches um $8^{3 / 4} \mathrm{Uhr}$ abends; um diese Zeit trank Gerhartz inmerhalb 10. Minuten 75,67 ccm Alkohol in ca. 50\% iger Lösung. Ca. 1/2 Stunde vorher hatte Dr. Gerhartz seine Abendmahlzeit zu sich genommen urd war auf dem Sofa sitzen geblieben; er stand auch während der nächsten $1^{3 / 4}$ Stunden nicht auf, um eine Erhöhung der Pulszahl durch willkürliche Muskelbewegungen auszuschliessen. Der eine von uns bestimmte jede Viertelstunde die Pulszahl und notierte sonstige Beobachtungen. Es wurde folgendes im Protokoll vermerkt:

\begin{tabular}{|c|c|}
\hline Zeit: & Pulszahl: \\
\hline 9 h $3^{\prime}$ & 63 \\
\hline 9 h $18^{\prime}$ & 61 (sehr kräftjger Puls), \\
\hline 9 h $33^{\prime}$ & 65 (leichter Rausch, starke Transpiration), \\
\hline 9 h $48^{\prime}$ & 61 (schwache Transpiration), \\
\hline $10^{\mathrm{h}} \quad 3^{\prime}$ & $\begin{array}{l}63 \text { (Transpiration normal, subjektiv der leiehte } \\
\text { Rausch im Abllingen), }\end{array}$ \\
\hline $10^{\mathrm{h}} 18^{\prime}$ & $\begin{array}{l}62 \text { (ein leichter Rauschzustand macht sich wieder } \\
\text { bemerkbar), }\end{array}$ \\
\hline $10^{\mathrm{h}} 33^{\prime}$ & 62 \\
\hline $10^{h} 48^{\prime}$ & 62 (das subjektive Befinden ist wieder normal). \\
\hline
\end{tabular}

Die Abweichungen bezüglich der Pulszahl sind so gering, dass man nur folgern kann: Dr. Gerhartz ist durch die immerhin ziemlich starke Alkoholdosis nur wenig alteriert worden. Die erste Harnentleerung erfolgte um $11^{\mathrm{h}} 16^{\prime}$ abends, also $2^{1 / 2}$ Stunden nach der Alkoholaufnahme. Die zweite Harnentleerung fand um $2^{\text {h }}$ nachts, die dritte um $8 \mathrm{~h}$ morgens statt, die vierte um $10^{\mathrm{h}} 10^{\prime}$, die fünfte 
um $2^{\mathrm{h}} 15^{\prime}$, die sechste um 5 h $10^{\prime}$, die siebente um $6 \mathrm{~h} 15^{\prime}$ und die achte um $7 \mathrm{~h} 30 \%$. Der Harn wurde stets in eine Glasflasche direkt entleert, die etwas Salzsäure enthielt und regelmässig wieder gut verkorkt wurde, ebenso wie in den analogen Versuchen an den beiden anderen Herren. Der gesamte Harn wurde bereits am nächsten Tage zweimal destilliert und der Alkohol im zweiten Destillat nach Nicloux bestimmt. Wir fanden $0,199 \mathrm{cem}$ Alkohol entsprechend $0,26 \%$ der Zufuhr. Dieser. Wert stimmt befriedigend mit dem von Atwater und Benedict (l.c.) gefundenen Mittelwert überein. Die amerikanischen Forscher hatten ungefähr die gleiche Alkoholmenge, allerdings in sechs Dosen über den Tag verteilt, an ihre Versuchspersonen verabreicht.

\section{Versuch an Dr. med. Förster am 28./24. April 1910.}

Dr. Förster ist $32 \mathrm{Jahre}$ alt, ca. $60 \mathrm{~kg}$ sehwer, gesund, von grazilem Körperbau und an regelmässigen Alkoholgenuss nicht gewöhnt.

Längere Zeit vor dem. Versuch hatte Dr. Förster keinen Alkobol aufgenommen. $\mathrm{Am}$ 23. April $12^{3 / 4}$ mittags trank Dr. Förster $63,05 \mathrm{ccm}$ ca. $50 \%$ igen Alkohol in einer Dosis und bestimmte nach verschiedenen Zeitabschnitten seine Pulsfrequenz, die sehr abweichende Zahlen ergab; und aus denen keine Schlüsse za ziehen sind; weil dieselben zum Teil durch willkürliche Muskelbewegungen bei der Laboratoriumstätigkeit mit bedingt waren. In dem innerhalb 24 Stunden nach dem Alkoholgenuss gesammelten Harn wurden $0,720 \mathrm{ccm}$ Alkohol resp. 1,14\%. wiedergefunden; diese Menge ist etwa viermal so gross, als die bei Dr. Gerhartz ermittelte. Zum Teil mögen die Differenzen durch die Individualität bedingt sein; in der Hauptsache dürfte jedoch die stärkere diuretische Wirkung des Alkohols bei Dr. Förster; der längere Zeit vor dem Versuch keinen Alkohol genossen hatte, zu der vermehrten Alkoholausscheidung im Harn geführt haben. Ausserdem dürfte auch die Tageszeit und der Füllungszustand des Magendarmkanals von Einfluss auf die im Harn zur Ausscheidung gelangende Alkoholmenge sein. Im äusșeren Verbalten Dr. Försters wurden Störungen nicht bemerkt.

3. Versuch an Dr. phil. Baudrexel am 19.20. April 1910.

$\mathrm{Baudrexel}$ ist 27 Jahre alt, $67 \mathrm{~kg}$ schwer, er ist gesund und besitzt gut entwickelte Muskulatur; er ist an mässigen Alkoholgenuss gewöhnt. Einen Tag vor dem Versuch wurde kein Alkohol genossen. Am 19. April $12^{3 / 4}$ h trank Baudrexel während des Mittagessens 
allmählich 55,20 ecm Alkohol in 20\% iger Lösung; er fand folgende Zahlen für seine Pulsfrequenz:

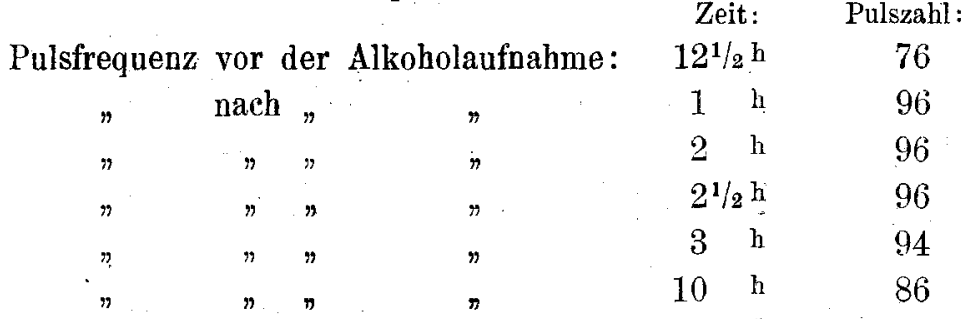

Bei Dr. B a udrexel wirkte die Alkoholdosis stark berauschend, er empfand beispielsweise um $1^{\mathrm{h}}$ Schwindel, immerhin konnte er seine Tätigkeit im Laboratorium fortsetzen, wenngleich seine Geschicklichkeit etwas beeinträchtigt erschien (er zerbrach einige Gläser). Offenbar wurde er stärker durch die Alkoholdosis alteriert als die beiden anderen Herren, das geht z. B. auch aus der Steigerung der Pulsfrequenz hervor, die allerdings zum Teil durch die Nahrungszufuhr und willkürliche Muskelbewegungen bedingt war.

In dem innerhalb 24 Stunden nach der Alkoholzufuhr durch sechsmaliges Urinieren gewonnenen Harn wurden $0,128 \mathrm{ccm}$ Alkohol resp. $0,23 \%$ der Zufuhr wiedergefunden, ein Wert, der mit dem von den amerikanischen Forschern (1. c.) angegebenen Mittelwert und dem an Dr. Gerbartz gefundenen befriedigend übereinstimmt. Wir beabsichtigen den Finfluss verschiedener Faktoren auf die vom menschlichen Organismus im Harn zur Ausscheidung gelangenden Alkoholmengen in besonderen Versuchen eingehender $\mathrm{zu}$ studieren.

Tabellarische Übersichten.

Schliesslich haben wir noch die Resultate der Versuche an den Hunden Nr. I und Nr. II tabellarisch und in Kurven abersichtlich zusammengestellt. Die Tabelle 14 enthält die diesbezüglichen Daten für den älteren Teckel Nr. I, Tabelle 15 diejenigen für den jungen Hund Nr. II, aus Tabelle 16 ist die Menge der reduzierenden Stoffe ersichtlich, die bei alkoholfreiem Regime durch die Atmung abgegeben werden. Die erste Kurventafel auf Seite 129 mit den Kurven Nr. I und Nr. II lässt den Einfluss der Gewöhnung und des Flüssigkeitsvolumens auf die Ausscheidung des Alkohols in Harn und Atmung nach der Zufuhr von ca. $3 \mathrm{ccm}$ pro Körperkilogramm bei dem alten Teckel Nr. I erkennen. Die Kurve III bezieht sich auf die Versuche mit dem jungen Hund Nr. II, der ca. $1 \mathrm{ccm}$ Alkohol pro Körperkilogramm in 9,84\% iger Lösung erhielt. 
Wilhelm Völtz und August Baudrexel:

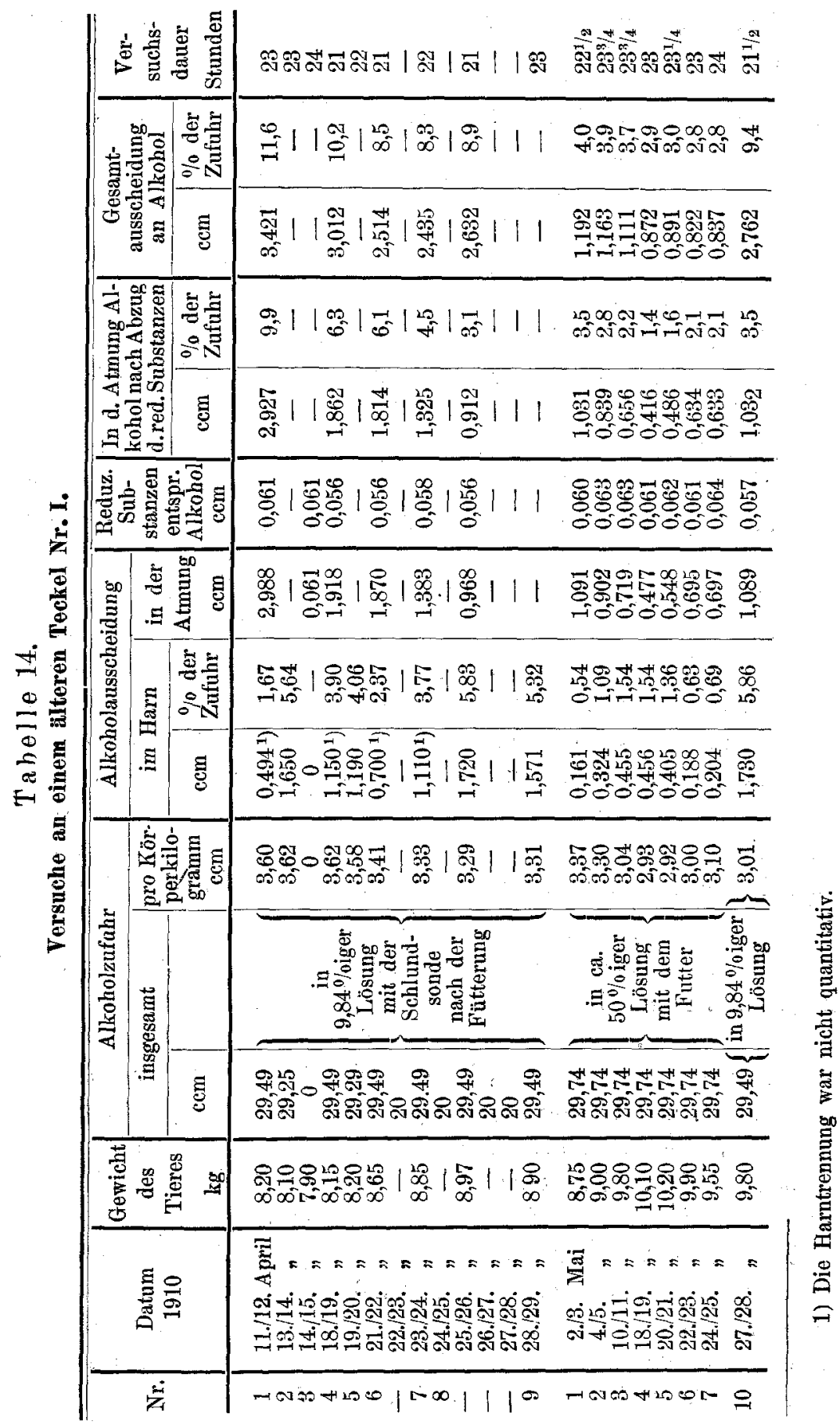


Über die vom tierischen Organismus ausgeschiedenen Alkoholmengen. 127

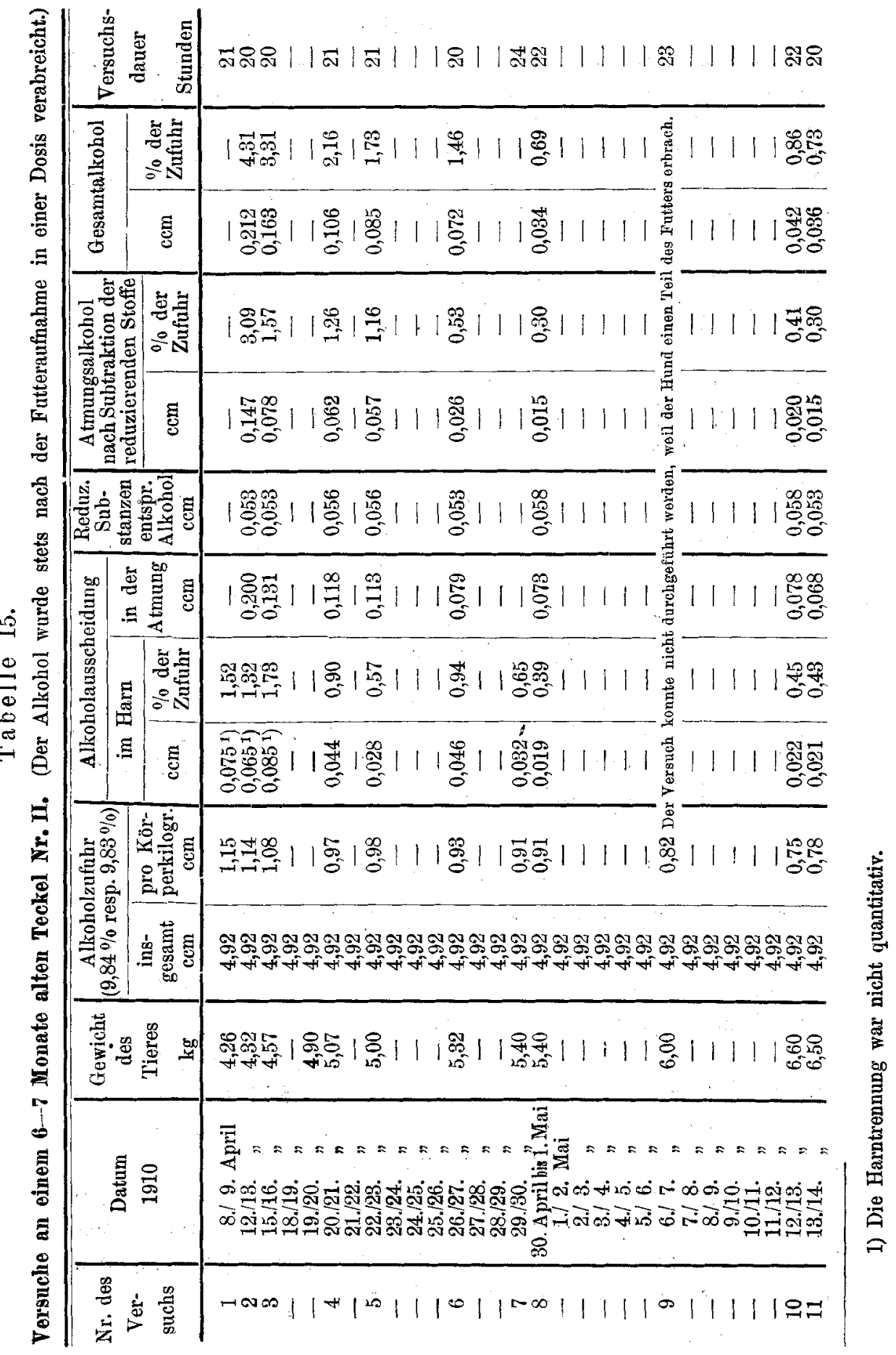




\section{Tabelle 16.}

Versuche 1-4: Menge der während eines Hungertages nach vorheriger normaler Ernährung innerhalb 18-23 Stunden in der Atmung ausgeschiedenen reduzierenden Stoffe entsprechend Kubikzentimeter Alkohol. Versuche 5 und 6 : Menge der nach neun- resp. sechstägigem Hunger in der A'tmung innerhalb 22 Stunden ausgeschiedenen reduzierenden Substanzen entsprechend Kubikzentimeter Alkohol.

\begin{tabular}{|c|c|c|c|c|c|}
\hline $\begin{array}{l}\text { Ver- } \\
\text { such } \\
\text { Nr.: }\end{array}$ & $\begin{array}{c}\text { Datum } \\
1910\end{array}$ & $\begin{array}{l}\text { Bezeichnung } \\
\text { des Tieres }\end{array}$ & $\begin{array}{c}\text { Gewicht } \\
\text { des'Tieres } \\
\text { kg }\end{array}$ & $\begin{array}{c}\text { Reduzie- } \\
\text { rende Sub- } \\
\text { stanzen ent- } \\
\text { sprechend } \\
\text { ech Alkohol }\end{array}$ & $\begin{array}{l}\text { Versuchs- } \\
\text { dauer } \\
\text { Stunden }\end{array}$ \\
\hline $\begin{array}{r}1 \\
2 \\
3 \\
4\end{array}$ & $\begin{array}{l}\text { 5./6. April } \\
13 . / 14 . \\
14.15 . " \\
19 . / 20 . "\end{array}$ & $\begin{array}{c}\text { Hündin } \\
\text { alter Teckel } \\
\text { alter Teckel I } \\
\text { alter Teckel }\end{array}$ & $\begin{array}{l}3,81 \\
9,89 \\
7,90 \\
9,60\end{array}$ & $\begin{array}{l}0,050^{-} \\
0,063 \\
0,061 \\
0,054\end{array}$ & $\begin{array}{l}23 \\
18 \\
24 \\
22\end{array}$ \\
\hline
\end{tabular}

Alșo im Mittel von 24 Stunden $0,064 \mathrm{ccm}$ (pro Stunde $0,00266 \mathrm{ccm}$ ).

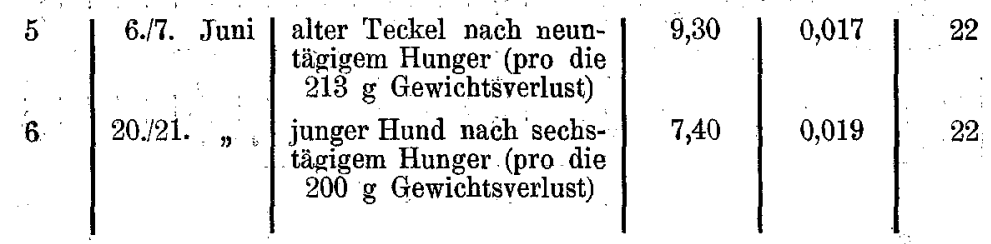

In weiteren Versuchen beabsichtigen wir, den Einfluss der Muskelarbeit und der Dosierung auf die Ausscheidung des Alkohols in Harn und Atmung zu studieren.

\section{Zusámmenfassung der Resultate.}

1. Von 4-10 kg schweren Hunden wird innerhalb eines Hungertages nach vorheriger normaler Ernährung bei alkohoffreiem Regime eine im Mittel 0,064 cem Alkohol entsprechende Menge reduzierender Stoffe durch die Atmung ausgeschieden.

2. Nach 6-9 tägigem Hunger entsprechen die von Hunden gleicher Grösse innerhalb desselben Zeitraumes (24 Stunden) an die ausgeatmete Luft abgegebenen reduzierenden Stoffe ca. $0,02 \mathrm{ccm}$ Alkohol, das ist etwa ein Drittel des unter 1. angegebenen Wertes. -

Bezüglich des Einflusses der aufgenommenen Alkohol menge (A), der Gew ơhnư g (B) und des gleichzeitig verabreichten Flüssigkeitsvolumens (C) auf die Alkoholausscheidung in Harn und Atmung wurde folgendes konstatiert: 
Über die vom tierischen Organismus ausgeschiedenen Alkoholmengen. 129

A. Einfluss verschiedener Alkoholmengen gleicher Konzentration $(9,84 \%$ ig) auf die Alkobolausscheidung durch den Organismus des an Alkohol nicht gewöhnten Hundes.

1. Nach der Zufuhr von ca. 3 cem Alkohol pro Körperkilogramm in einer Dosis werden insgesamt $10-12{ }^{0} \%$ der Zufuhr aus-

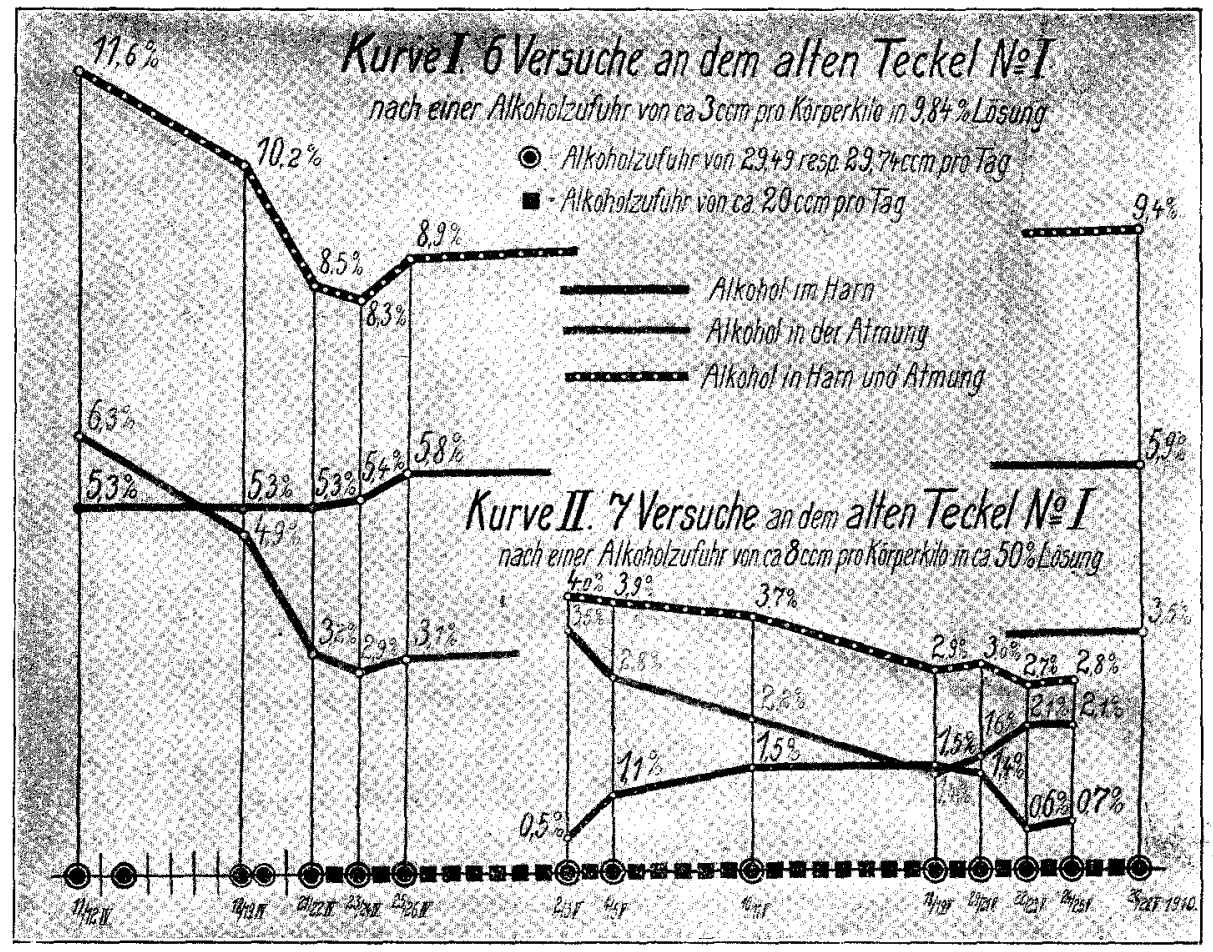

geschieden, und zwar ungefähr zur Hälfte durch die Atmung, zur anderen Hälfte durch die Nieren.

2. Nach einer Alkoholdosis von $0,75-1,15$ cem pro Körperkilogramm und Tag werden insgesamt $2,6-4,3 \%$ der Zufuhr wieder ausgeschieden, also ca. nur $1 / 4-1 / 3$ der Menge, welche nach der dreifachen Dosis zur Ausscheidung gelangt. Die Quantität des aufgenommenen Alkohols ist also von grossem Einfluss auf die Alkoholausscheidung in Harn und Atmung. Was das Verhältnis der Harnalkohols zum Alkohol der Atmung anbelangt, so scheiden Hunde, welche durch die Alkoholzufuhr stärker alteriert werden; infolge 
forzierter Atmung grössere Alkoholmengen durch die Atmung aus; Hunde, welche auf gleiche Alkoholdosen weniger stark reagieren, scheiden einen höheren Prozentsatz Alkohol durch die Nieren aus, einen geringeren durch die Atmung.

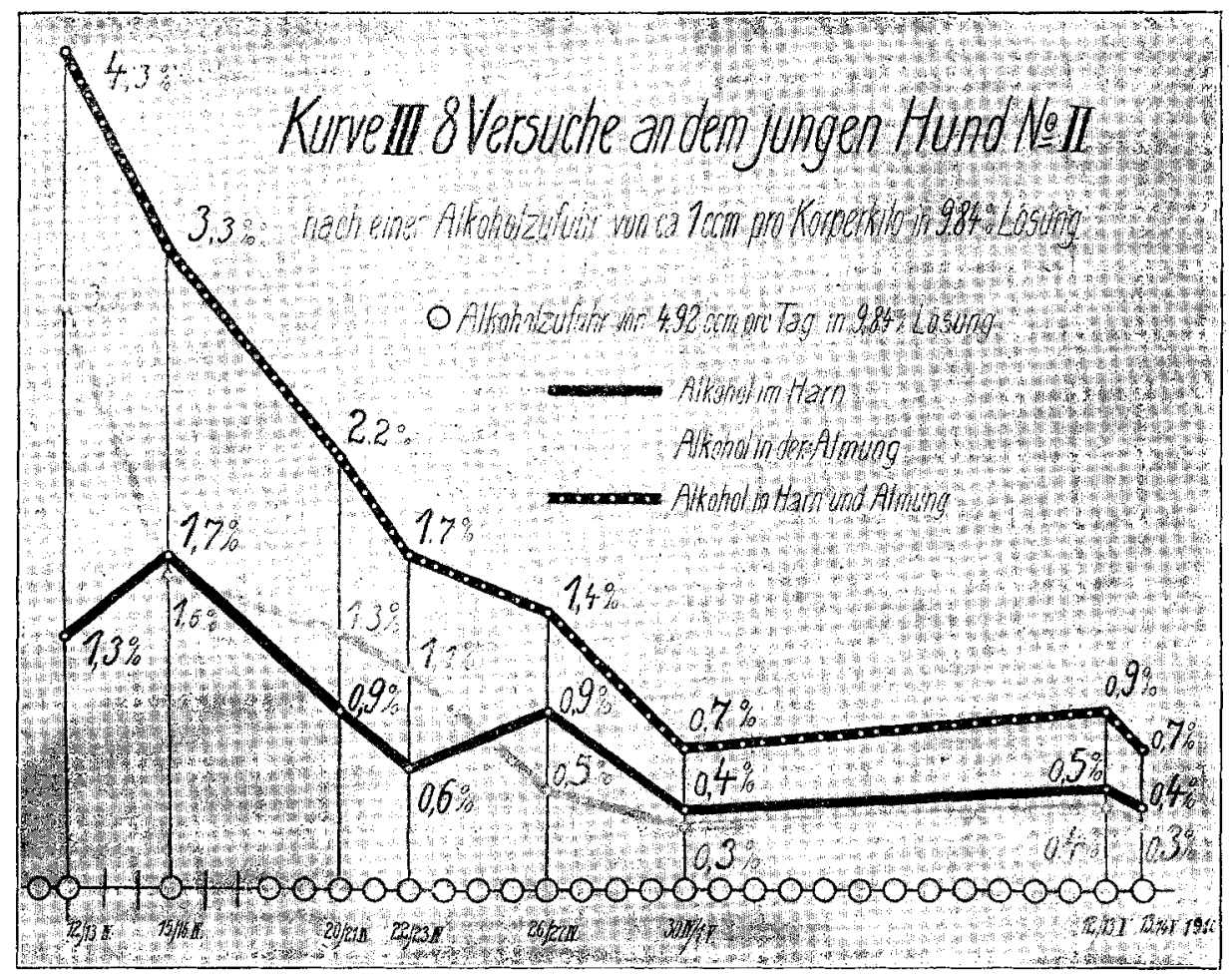

B. Einfluss der Gewöhnung auf die vom Organismus des Hundes ausgeschiedenen Alkoholmengen.

1. Nach einer Alkoholdosis von ca. 3 cem pro Körperkilogramm and Tag in 9,81\% \%ger Lösung werden vom Hunde zunächst insgesamt $10-12 \%$ der Zufubr wieder ausgeschieden. Im Verlaufe von 10-12 Tagen sinkt dieser Wert unter dem Einfluss der Gewöhnung auf $8,3 \%$, also um rund $30 \%$ der ursprünglichen Menge und kann dureh weitere Gewöhnung nicht mehr untersehritten werden. Zunächst erscheinen in Harn und Atmung ungefähr gleiche Mengen Alkohol, später nimmt der ausgeatmete Alkohol kontinuierlch $a b$, so dass schliesslich zwei Drittel der gesamten ansgeschiedenen Alkoholmenge mit dem Harn und ein Drittel mit der Atmung den Körper verlassen, 
Ǔber die vom tierischen Organismus ausgeschiedenen Alkoholmengen. $\quad 131$

d. h. die Ausscheidung durch den Harn bleibt unverändert, die durch die Atmung sinkt etwa auf die Hälfte des Anfangswertes (von $6,3 \%$ auf $3 \%$ ).

2. Nach der Zufuhr gleicher Alkoholmengen in stärkerer Konzentration $(50 \% \mathrm{ig})$ wird von dem an diese Alkoholquantität in starker Verdünnung $(9,84 \% \mathrm{ig})$ gewöhnten Tier von vornherein ein weit geringerer Prozentsatz Alkohol (etwa die Hälfte, siehe unter C 2.) ausgeschieden. Unter dem Einfluss der Gewöhnung sinkt der betreffende Wert innerhalb 3 Wochen noch um ein Drittel und dann nicht mehr weiter ab. Es gelangen in der Atmung doppelt so grosse Mengen Alkohol zur Ausscheidung als durch den Harn (siehe unter C 2.).

3. Nach der Zufuhr von $0,7-1,15 \mathrm{ecm}$ Alkohol pro Körperkilogramm und Tag in einer Dosis und in 9,84\% iger Lösung werden vom Hunde zunächst insgesamt rund $4 \%$ des aufgenommenen Alkohols ausgeschieden. Dieser Wert wird unter dem Einfluss der Gewöhnung kontinuierlich geringer, bis nach ca. 3 Wochen die unterste Grenze bei zirka einem Sechstel der ursprünglich ausgeschiedenen Menge erreicht ist. Durch weitere Gewöhnung kann der nach ca. 3 Wochen gefundene Minimalwert nicht mehr unterschritten werden; derselbe bleibt von da ab annähernd konstant.

Wir ersehen also aus diesen Resultaten, dass nach der Aufnahme von ca. $1 \mathrm{ccm}$ Alkohol pro Körperkilogramm und Tag, also einer Quantität, die, wenn sie in mehreren Dosen über den Tag verteilt genossen wird, nach den Versuchen von At water und Benedict (1. c.) vom Menschen zu ca. $98 \%$ verwertet wird, vom Hunde trotz de Verabreichung in einer Dosis nur 0,7-0,9\% der Zufuhr insgesamt ausgeschieden werden.

Die Verwertung des Alkohols durch den tierischen Organismus ist also unter diesen Bedingungen eine ausserordentlich hohe, sie beträgt über $99 \%$.

Bezüg]ich des Verhältnisses der durch die Atmung ausgeschiedenen Alkoholmengen relativ zum Harnalkohol ist hervorzuheben, dass zunächst infolge stärkerer Alteration des 'Tieres und dadurch bedingter forzierterer Atmung mehr Alkohol in der Atmung erschien, später wurde relativ mehr Alkohol durch die Nieren sezerniert.

Die höhere Verwertung des Alkohols im Organismus an Alkohol gewöhnter Tiere erklärt sich ungezwungen aus der verringerten Diurese und einer weniger starken Atmung. Der Alkohol hleibt also 
bei Tieren, die an denselben gewöbnt sind, längere Zeit in den Geweben und wird daher zu einem höberen Prozentsatz oxydiert, als bei nicht daran gewöhnten Tieren. Für eine Vermehrung der Alkoholoxydase unter dem Einfluss der Gewöhnung an Alkohol sprechen unsere Resultate nicht.

C. Einfluss der gleichzeitig mit dem Alkohol aufgenommenen Flüssigkeitsmenge auf die Alkoholansscheidung.

1. Nach der Zufuhr von ca. $3 \mathrm{ccm}$ Alkohol pro Körperkilogramm und Tag in $9,84 \%$ iger Lösung und in einer Dosis wurden vom Hunde zunächst $11,6 \%$ des verabreichten Alkohols ausgeschieden. Dieser Wert sank unter dem Einfluss der Gewöhnung um ca. 30\%. Infolge der durch die grosse Flüssigkeitsmenge bedingten starken Diurese erscheint die Hauptmenge des Alkohols mit Ausnahme des ersten Versuchstages im Harn.

2. Nach Verabreichung derselben Alkoholmenge (ca. $3 \mathrm{ccm}$ pro Körperkilogramm und Tag) in konzentrierterer Form (ca. $50 \%$ ig), d. b. in etwa einem Fünftel des unter 1. angegebenen Flüssigkeitsvolumens, werden insgesamt nur $4 \%$ der Zufubr vom Organismus ausgeschieden, also rund nur die Hälfte der Menge, welche nach Aufnahme derselben Alkoholquantität in einem etwa fünfmal so grossen Flüssigkeitsvolumen, bei dem an Alkohol gewöhnten Hund gefunden wurde. Allmählich sinkt dieser Wert mehr und mehr ab, bis das Minimum bei 2,7\%, also zwei Drittel der zu Beginn der Versuche gefundenen Menge erreicht ist: Die Diurese ist hier infolge weit geringerer Flüssigkeitsaufnahme viel schwächer, infolgedessen kann ein höherer Prozentsatz Alkohol verwertet werden, und es gelangt verhältnismässig mehr (etwa die doppelte Menge) Alkohol in der Atmung zur Ausscheidung als im Harn.

D. Ausscheidung des Alkohols in Atmung und Harn während einzelner Zeitabschnitte der betreffenden Versuchstage.

I. Ausscheidung des Alkohols in der Atmung.

Nach Alkoholgaben von 3,3-4,5 ccm Alkohol pro Körperkilogramm wurde beim Hunde das Maximum des in der Atmung ausgeschiedenen Alkohols in der dritten Stunde gefunden.

Während der zweiten und vierten Stunde blieb die Alkoholausscheidung durch die Atmung etwa um ein Drittel gegenüber dem Maximum in der dritten Stunde zurück. 
Während der ersten Stunde war der Alkoholgehalt der Atmung um etwa zwei Drittel geringer als dem Höchstwert der dritten Stunde entsprach. Auch während der fünften. Stunde werden noch $20 \%$ mehr Alkohol durch die Atmung ausgeschieden, als während der ersten Stunde nach der Alkoholzufuhr.

\section{Ausscheidung des Alkohols im Harn.}

ca. 11/2-2 Stunden nach der Zufuhr von $3 \mathrm{cem}$ Alkohol pro Körperkilogramm in $9,84 \%$ iger Lösung werden weit über die Hälfte des überhaupt durch die Nieren sezernierten Alkohols im Harn wiedergefunden.

E. Ausscheidung des Alkohols im Harn des Menschen.

In je einem Versuch an zwei Personen und in zwei Versuchen an einer dritten Person wurden nach Zufuhr von $0,8-1 \mathrm{ccm}$ Alkohol pro Körperkilogramm und Tag in einer Dosis: 0,23\%, 0,24\% (l. c. S. 85), $0,26 \%$ und $1,14 \%$ der zugeführten Alkoholmenge m Harn wiedergefunden. 